\title{
Synaptic and Morphological Neuroadaptations in the Putamen Associated with Long-Term, Relapsing Alcohol Drinking in Primates
}

\author{
Verginia C Cuzon Carlson', Gail K Seabold², Christa M Helms ${ }^{3}$, Natasha Garg ${ }^{2}$, Misa Odagiri', \\ Andrew R Rau ${ }^{3}$, James Daunais ${ }^{4}$, Veronica A Alvarez ${ }^{2}$, David M Lovinger*,I and Kathleen A Grant*,3,5 \\ 'Laboratory for Integrative Neuroscience, Section on Synaptic Pharmacology, National Institute on Alcohol Abuse and Alcoholism, NIH, \\ Rockville, MD, USA; ${ }^{2}$ Laboratory for Integrative Neuroscience, Section on Neuronal Structure, National Institute on Alcohol Abuse and \\ Alcoholism, NIH, Rockville, MD, USA; ${ }^{3}$ Division of Neuroscience, Oregon National Primate Research Center, Oregon Health and Science \\ University, Portland, OR, USA; ${ }^{4}$ Department of Physiology and Pharmacology, Wake Forest University School of Medicine, Winston-Salem, \\ NC, USA; ${ }^{5}$ Department of Behavioral Neuroscience, Oregon Health and Science University, Portland, OR, USA
}

\begin{abstract}
Alcoholism and alcohol use disorders are characterized by several months to decades of heavy and problematic drinking, interspersed with periods of abstinence and relapse to heavy drinking. This alcohol-drinking phenotype was modeled using macaque monkeys to explore neuronal adaptations in the striatum, a brain region controlling habitual behaviors. Prolonged drinking with repeated abstinence narrowed the variability in daily intake, increased the amount of ethanol consumed in bouts, and led to higher blood ethanol concentrations more than twice the legal intoxication limit. After the final abstinence period of this extensive drinking protocol, we found a selective increase in dendritic spine density and enhanced glutamatergic transmission in the putamen, but not in the caudate nucleus. Intrinsic excitability of medium-sized spiny neurons was also enhanced in the putamen of alcohol-drinking monkeys in comparison with non-drinkers, and GABAeric transmission was selectively suppressed in the putamen of heavy drinkers. These morphological and physiological changes indicate a shift in the balance of inhibitory/excitatory transmission that biases the circuit toward an enduring increase in synaptic activation of putamen output as a consequence of prolonged heavy drinking/relapse. The resultant potential for increased putamen activation may underlie an alcohol-drinking phenotype of regulated drinking and sustained intoxication.

Neuropsychopharmacology (20 I I) 36, 25 I3-2528; doi:I0. I038/npp.20 I I. I 40; published online 27 July 20 I I
\end{abstract}

Keywords: self-administration monkeys; alcohol; caudate/putamen; synaptic morphology; glutamatergic transmission; GABAergic transmission

\section{INTRODUCTION}

World Health Organization studies indicate that $>2$ billion people drink alcohol and that $\sim 76$ million suffer from alcoholism or alcohol use disorders worldwide. Alcoholism is a chronic disease in which episodes of heavy and problematic drinking are interspersed with periods of abstinence and relapse (Edwards and Gross, 1976). Prominent features of alcoholism are the alcoholic's awareness of the compulsion to drink and repeated efforts to reduce consumption (Edwards and Gross, 1976), which increases the occurrence of abstinence. Although abstinence is crucial for recovery, it

*Correspondence: Dr KA Grant, Division of Neuroscience, Department of Behavioral Neuroscience, Oregon National Primate Research Center, Oregon Health and Science University, Portland, OR, USA, Tel: + I 503 6I4 3738, Fax: + I 503690 5384,

E-mail: grantka@ohsu.edu or lovindav@mail.nih.gov

Received 26 April 201 I; revised I4 June 201 I; accepted I5 June 201 I is not innocuous, but rather produces plasticity in neural and behavioral processes that contribute to more compulsive drinking. In rodent models, periods of abstinence from chronic alcohol exposure alter subsequent alcohol self-administration patterns increasing intake and blood ethanol concentration (BEC) compared with animals that do not experience repeated abstinence (Becker and Lopez, 2004; Lopez and Becker, 2005). Similarly, attempts by problem drinkers to abstain with formal treatment programs can be followed by periods of increased alcohol consumption (Delucchi and Kaskutas, 2010). Studies have yet to reveal how heavy drinking over several months to years with periods of repeated abstinence could alter neuronal circuits and drinking repertoire, such that daily drinking to intoxication becomes a highly regulated behavior (Wetterling et al, 1999).

Alcoholism is an excellent example of the transition from an easily modulated behavior to a 'habit of drunkenness' (Edwards, 2010). The dorsal striatum and associated basal 
ganglia (BG) circuitry have key roles in controlling instrumental (ie, operant) learning and the development of habitual performance of these learned behaviors (Balleine et al, 2007). The dorsal striatum is divided into two subregions, the proposed roles of which are consistent with their anatomical connections. The anterior portion of the caudate nucleus (similar to the dorsomedial striatum in rodents) seems to mediate conditioned behavior in concert with 'associative circuit' brain regions, such as the prefrontal cortex (Yin et al, 2005a, b; Haber et al, 2006; Gläscher et al, 2009). The caudoventral area of the putamen nucleus (similar to the dorsolateral striatum in rodents) and associated 'sensorimotor' structures seem to mediate habit formation (Yin et al, 2006; Tricomi et al, 2009). Within the striatum, medium-sized spiny neurons (MSNs) constitute $95 \%$ of total neurons, and receive convergent glutamatergic afferents from the cortex and thalamus, as well as dopaminergic afferents from the substantia nigra. As the only output from the striatum, MSNs link these nuclei to the rest of the BG.

To model chronic ethanol (EtOH) use, a 3-year longitudinal study of EtOH self-administration with forced abstinence periods in cynomolgus macaque monkeys was developed. This model examined two of the original (Edwards and Gross, 1976) and continuing (Diagnostic and Statistical Manual of Mental Disorders (DSM-IV), 1994) criteria for the diagnosis of alcohol dependence in humans. In particular, these diagnostic criteria are: (1) 'reinstatement after abstinence' or relapse and (2) 'narrowing in the drinking behavior repertoire' or stereotyped drinking (Edwards and Gross, 1976). The narrowed drinking repertoire was further described as 'with advanced dependence the drinking may become stereotyped; scheduled to a daily time table to maintain a high blood alcohol' (Edwards and Gross, 1976). Finally, the criteria of 'reinstatement after abstinence' were discussed in terms of 'relief of withdrawal' and 'fear of withdrawal,' suggesting that the dependent individual learns to avoid withdrawal by maintaining high levels of circulating alcohol. These levels documented in alcoholics range between 150 and $450 \mathrm{mg} / \mathrm{dl}$ (Majchrowicz and Mendelson, 1971).

Alcohol consumption in our macaque model resembles human alcoholic drinking, including 'sprees' of high intake, drinking outside meal times, periods of self-imposed abstinence, and loss of circadian control over drinking (Grant et al, 2008a, b; Monti et al, 2004). Chronic alcohol intakes also result in adverse physiological consequences to the liver, heart, blood, and brain (Carden et al, 2006; Hemby et al, 2006; Walker and Grant, 2006; Freeman et al, 2006; Ivester et al, 2007; Acosta et al, 2010; Cheng et al, 2010; Freeman et al, 2010; Lebold et al, 2011). However, the effects of a multi-year protocol of EtOH self-administration with repeated abstinence have not been reported, and we hypothesized that adaptations in aspects of striatal function likely contributes to stereotyped heavy drinking behavior. Thus, at necropsy, we examined synaptic transmission, dendritic spine morphology, and neuronal excitability of striatal circuitry. Our findings indicate increased potential for synaptic and intrinsic activation of putamen MSNs after prolonged EtOH intake/abstinence. These neurobiological changes are related to status as a heavy drinker, average BECs, and cortisol response to drinking/abstinence state, and therefore likely contribute to a pattern of alcoholdrinking phenotypes in the non-human primate.

\section{MATERIALS AND METHODS}

\section{Chronic Intermittent Oral Ethanol Self-Administration}

A total of 16 adult (7-9.5 years old) male cynomolgus monkeys (Macaca fascicularis) were purchased from World Wide Primates (Miami, FL). Upon release from quarantine, the monkeys were individually housed in the same room in cages containing an operant panel with two drinking spouts, a central food cup, and instrumentation that provides accurate measures of the amount and temporal pattern of drinking (detailed protocol in the study by Grant et al $(2008 \mathrm{a}, \mathrm{b}))$. Drinking records were categorized as 'bouts' (continuous fluid displacement with $<5 \mathrm{~min}$ between instances). During data analysis, consumption totals and timing of events were processed to achieve totals for each bout and full session.

In all, 12 monkeys were induced and maintained on an EtOH self-administration protocol as described previously (Vivian et al, 2001; Grant et al, 2008a). Using a scheduleinduced polydipsia procedure, the monkeys were first induced to drink water and then a low concentration of $\mathrm{EtOH}(4 \% \mathrm{w} / \mathrm{v}$ in water) in specified volumes equivalent to $0.5,1.0$, and $1.5 \mathrm{~g} / \mathrm{kg}$ per day; each dose induced for 30 consecutive days over 120 days. After induction, sessions were increased to $22 \mathrm{~h}, \mathrm{EtOH}$ and water were available on separate spouts, and food was available in three meals separated by $2 \mathrm{~h}$. The monkeys had 14 months of drinking under these 'open-access' conditions, with the 7th and 14th months used for assessing pharmacological challenges to the hypothalamic-pituitary-adrenal (HPA) axis (Porcu et al, 2006). During this assessment of the HPA axis, 'open-access' conditions were in effect and cortisol measures were reported from a 0800 hours sample.

Monkeys were then given an additional 16 months of 'open access' to EtOH with 4-6 month durations interspersed with 28 days of EtOH abstinence with only water available (Figure 1a). EtOH self-administration data are described in terms of the three pre-abstinence phases. The morning after the 28th abstinence day of the third abstinence period, the monkeys were sent to necropsy.

Throughout the drinking protocol, the monkeys complied with awake venipuncture for obtaining blood for BEC analysis every 5-7 days at $7 \mathrm{~h}$ after the session onset as described previously (Grant et al, 2008a). Daily intake patterns of EtOH were evaluated across the three preabstinence phases. Previously, increased ability to drink large volumes in bouts was determined to be a characteristic of heavy-drinking monkeys (Grant et al, 2008a, b), and therefore was a primary dependent variable of interest. Control monkeys were placed on the same diet with water available ad libitum, in the same housing rooms, and had similar daily routines as that of EtOH-drinking animals.

\section{Abstinence-Associated Withdrawal Symptoms}

Behavioral signs of normal activity and EtOH withdrawal were noted by three independent observers, each assessing four focal monkeys over $15 \mathrm{~min}$ requiring $1 \mathrm{~h}$ of total observation. The observations were noted during 'intoxication' ( 6 days before, 3 days before, and at the time of $\mathrm{EtOH}$ removal), 'acute withdrawal' (at 24,48 , and $72 \mathrm{~h}$ of 
a

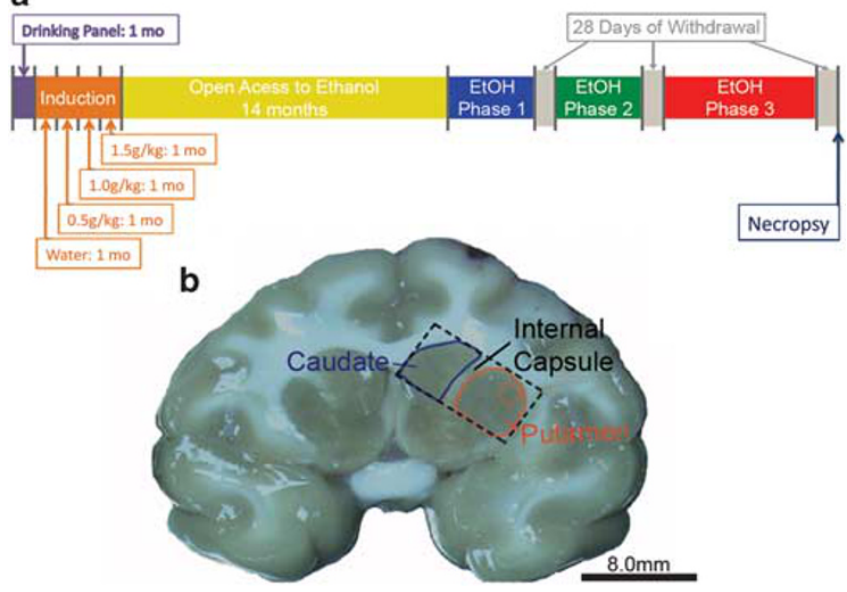

Figure I Experimental time line and examples of brain sections used for morphology and electrophysiology. (a) A model depicting the experimental time line. (b) Example of a 4-mm-thick brain section obtained from the sectioning of the monkey brain in a brain matrix. The caudate is outlined in blue. The putamen is outlined in red. The caudate and putamen are separated by the internal capsule. The section is further blocked for morphological and electrophysiological analyses and is denoted by a dashed box. The red box in the putamen denotes the area in which MSNs were targeted for electrophysiological recording.

abstinence), and 'prolonged withdrawal' (at 4, 17, and 21 days of abstinence). Signs of withdrawal included body shake ('wet dog shake'), tremor (spontaneous shake of any body part), intentional tremor (tremor seen when reaching for a raisin held outside the cage), huddle (hugging self with head' down), low affect (sitting in the back of the cage and indifferent to any noise or object), piloerection (raised body hair), anorexia (not eating the daily allotment of pellets), and vomit. These time points and withdrawal signs were based on early reports of physical' withdrawal from high doses of $\mathrm{EtOH}$ administered by intravenous or intragastric infusions (Ellis and Pick, 1971; Myers et al, 1972; Winger and Woods, 1973). However, alcohol dependence from voluntary oral EtOH self-administration has rarely been documented in non-human primates.

Normal behaviors were also noted during the same observation periods and included cage activity (playing with toys, responding on the panel, foraging in the bedding), self-directed behaviors (grooming, scratching, masturbation, chewing), and social activity (open mouth aggression, yawning, vocalization, lip smacking). Any occurrence of these signs was noted for each monkey and pooled over the time period.

\section{Statistical Analysis}

Log-transformed BECs, which conformed to a normal distribution, were used in all statistical analyses. Except for daily intake, EtOH bouts, and maximum bout number, all drinking measures were log transformed for statistical analysis. Linear mixed models included monkey as a repeated subject variable. The model covariance structure with the best fit was determined using Schwarz's Bayesian information criteria. Post hoc Tukey's tests were used to evaluate significant main effects and interactions. The number of times a behavioral withdrawal sign occurred was summed across the three observations for each phase (intoxicated, acute withdrawal, and prolonged withdrawal), and tested with Kruskal-Wallis nonparametric analysis of variance. All occurrences of normal behaviors within an observation phase were averaged for each monkey and subjected to analysis using the Kruskal-Wallis test. For all analyses, $\alpha<0.05$.

\section{Tissue Preparation for Electrophysiology}

Monkeys were anesthetized with ketamine $(10 \mathrm{mg} / \mathrm{kg})$ and maintained on isoflurane during the craniotomy procedure that optimizes the brain for subsequent electrophysiological procedures (Daunais et al, 2010). The brains were rapidly removed ( $\sim 5 \mathrm{~min}$ ) and placed dorsal side down in a brain matrix (Electron Microscopy Sciences, Hatfield, PA) designed to section the brain in the coronal plane using brain knives the position of which was guided by each individual's MRI (Figure 1b). The isolated tissue section was blocked to $\sim 10 \mathrm{~mm}$ wide $\times 8 \mathrm{~mm}$ high $\times 4 \mathrm{~mm}$ thick to contain only the caudate, putamen, and the overlying white matter. The tissue block was placed in a conical tube of icecold oxygenated perfusion solution and transported on ice for slicing. Tissue was then transferred to ice-cold cutting solution containing in mM: sucrose, $194 ; \mathrm{NaCl}, 30 ; \mathrm{KCl}, 4.5$; $\mathrm{MgCl}_{2}, 1 ; \mathrm{NaHCO}_{3}, 26 ; \mathrm{NaH}_{2} \mathrm{PO} 4,1.2$; and glucose, 10, aerated with a mixture of $95 \% \mathrm{O}_{2} / 5 \% \mathrm{CO}_{2}$ gas. Coronal slices at a thickness of $300 \mu \mathrm{m}$ were obtained using a ceramic blade (Camden Instruments Limited, Lafayette, IN) attached to a Vibroslicer (Leica, Buffalo Grove, IL). Slices were equilibrated for $1 \mathrm{~h}$ in aCSF containing in $\mathrm{mM}: \mathrm{NaCl}$, 124; $\mathrm{KCl}, 4.5 ; \mathrm{MgCl}_{2}, 1 ; \mathrm{NaHCO} 3,26 ; \mathrm{NaH}_{2} \mathrm{PO}_{4}, 1.2$; glucose, 10; and $\mathrm{CaCl}_{2}, 2$ continuously aerated with a mixture of $95 \%$ $\mathrm{O}_{2} / 5 \% \quad \mathrm{CO}_{2}$ gas at a temperature of $33^{\circ} \mathrm{C}$. Slices were transferred to room temperature until experimental use.

\section{Electrophysiology}

Slices were transferred to a recording chamber fixed to the stage of an upright microscope (Axioskop2, Zeiss, Thornwood, NY), stabilized by an overlying platinum ring, and continuously perfused with solution maintained at a temperature of $28-32{ }^{\circ} \mathrm{C}$ (Automatic Temperature Controller, Warner Instruments, Hamden, CT). MSNs were identified under infrared optics using a $\times 40$ water immersion objective. Real-time images aided the navigation and placement of the recording pipette. Recording patch pipettes were pulled from borosilicate glass capillaries $(1.5 \mathrm{~mm}$ outer diameter, $0.86 \mathrm{~mm}$ inner diameter, Sutter Instruments, Novato, CA) and filled with either $\mathrm{K}$-gluconate- or CsCl-based internal solutions. $\mathrm{CsCl}$ internal solution contained in $\mathrm{mM}$ : $\mathrm{CsCl}, 150$; HEPES, $10 ; \mathrm{MgCl}_{2}, 2$; Na-GTP, 0.3; Mg-ATP, 3; and BAPTA-4K, 0.2 was used. For current clamp recordings, a K-gluconate internal solution containing in mM: K-gluconate, 126; $\mathrm{KCl}, 4$; HEPES, 10; NaGTP, 0.3; Mg-ATP, 4; and phosphocreatine, 10 was used, and experiments were carried out in the absence of any receptor antagonists. Bicuculline $(30 \mu \mathrm{M})$ and tetrodotoxin (TTX; $1 \mu \mathrm{M}$ ) were added to aCSF when recording mEPSCs. D-(-)2-amino-5-phosphonopentanoic acid (D-APV; $50 \mu \mathrm{M})$, 2,3-dioxo-6-nitro-1,2,3,4-tetrahydrobenzo[f]quinoxaline-7- 

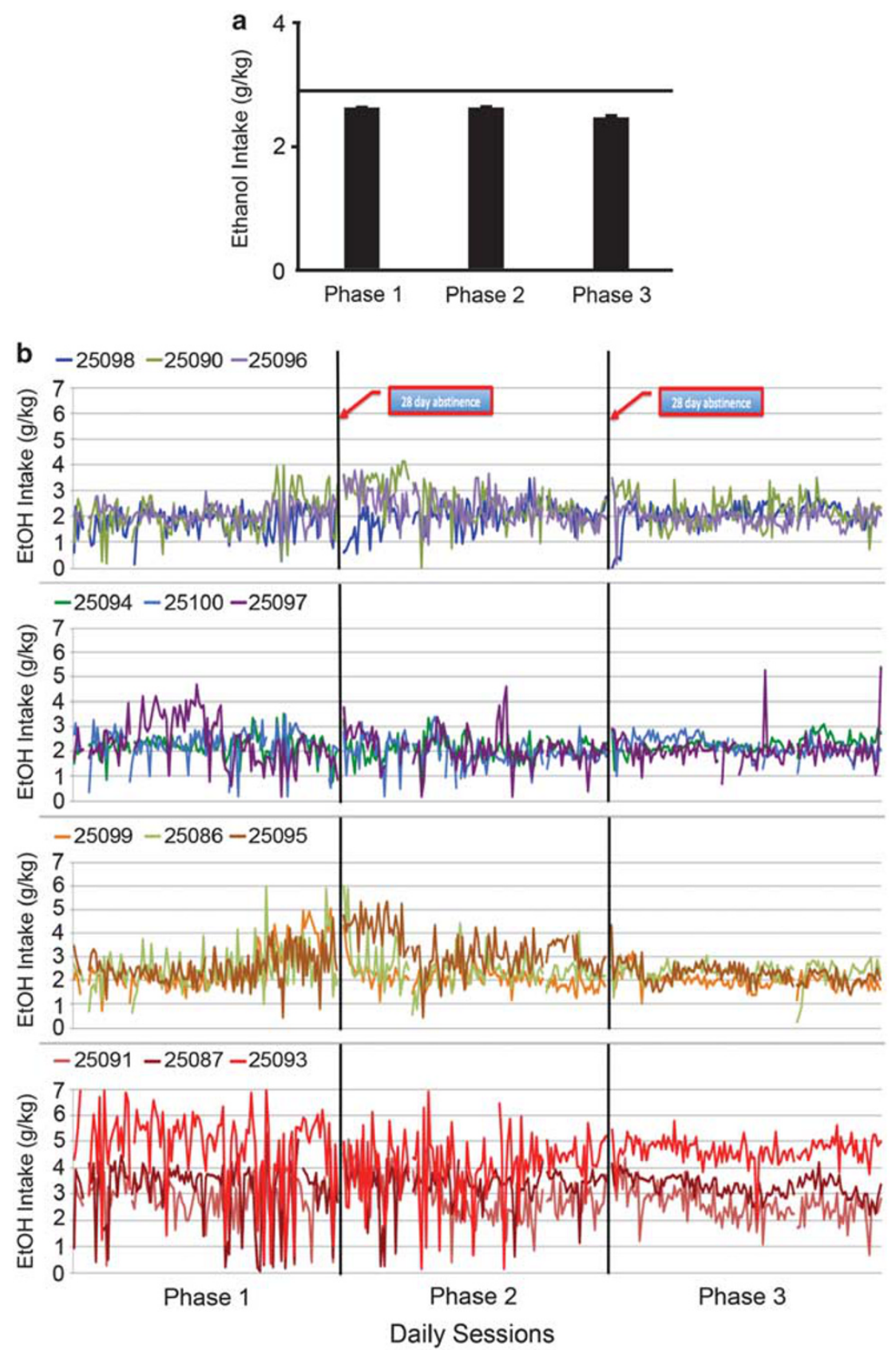

Figure 2 Repeated abstinence effects on ethanol daily intake. (a) Effects of repeated abstinence on mean ( $\pm \mathrm{SEM})$ daily ethanol (EtOH) intake $(\mathrm{g} / \mathrm{kg})$. The horizontal line indicates baseline EtOH intake measures averaged over 8 months preceding phase I (see Figure la for phases). (b) The variability in daily $\mathrm{EtOH}$ intake over the three phases in individual monkeys arranged from lowest (top) to highest (bottom) average daily drinkers. Variability in intakes decreased significantly from phase I to phase 3. Only four monkeys had short-term increases in intakes after the first abstinence $(25090,25096,25097$, 25 095), with three showing a short-term decline $(25098,25099,25086)$ and the rest showing no change in daily intakes. The second abstinence had little or no effect on average daily intakes.

sulfonamide (NBQX; $5 \mu \mathrm{M}$ ), and TTX were added to aCSF to isolate mIPSCs.

When filled with internal solution, the patch pipettes had a resistance or $2-4 \mathrm{M} \Omega$. Recordings were made using an AxoPatch 200B amplifier (Molecular Devices, Foster City, CA). Whole-cell membrane currents were filtered at $2 \mathrm{kHz}$, digitized using Clampex v8.0 and analyzed with Clampfit v8.0 (Molecular Devices, Sunnyvale, CA) or MiniAnalysis (Synaptosoft v6.0.7, Decatur, GA). Statistical analysis was performed using SigmaStat 3.0 (SPSS, Chicago, IL). Data are reported as mean \pm SEM.
Unless otherwise noted, all drugs were obtained from Tocris (Ellisville, MO). Bicuculline methiodide (Bicu; $10 \mathrm{mM}$; Sigma, St Louis, MO, USA), TTX (1 mM), D-APV $(50 \mathrm{mM})$, and NBQX $(5 \mathrm{mM})$ were dissolved in $\mathrm{ddH}_{2} \mathrm{O}$, stored as frozen stock, and diluted to working concentrations with aCSF immediately before each recording session.

\section{Diolistic Labeling}

The caudate, putamen, and the overlying white matter, obtained from the other half of the brain not used for 
Table I Average Daily EtOH Intakes (Mean \pm SD; g/ $\mathrm{kg}$ ) and Percentage of Heavy Drinking Days (Defined as $>4.0 \mathrm{~g} / \mathrm{kg}$ ) during the First 12 Months, Phase I, Phase 2, and Phase 3 of the Study

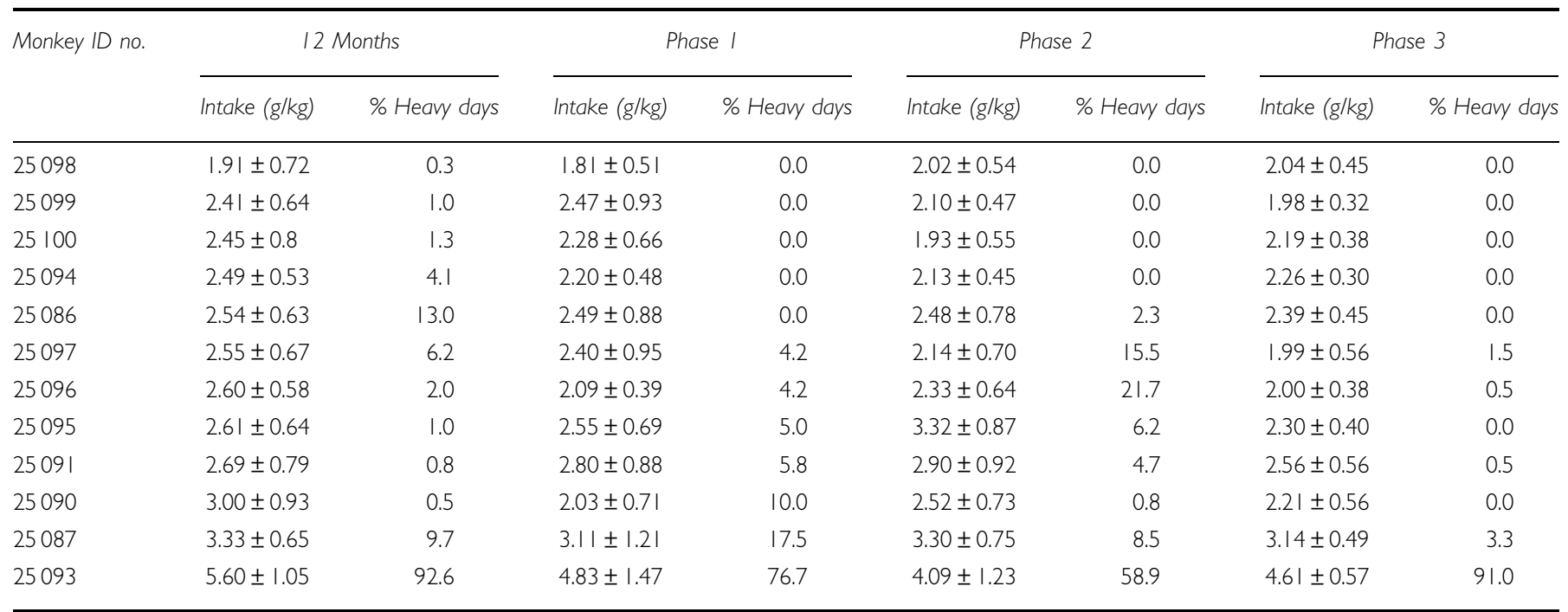

electrophysiology, were fixed in a solution of $4 \%$ paraformaldehyde and $4 \%$ sucrose in phosphate-buffered saline (PBS; $\mathrm{pH}=7.3$ ) for $60 \mathrm{~min}$ at room temperature. Tissue was then rinsed in PBS four times and kept at $4{ }^{\circ} \mathrm{C}$. The block of fixed tissue was cut using a vibratome. Coronal sections of $200-\mu \mathrm{m}$ thickness were stained using Diolistic labeling (Seabold et al, 2010). In brief, tungsten beads $(1.7 \mu \mathrm{m}$ diameter, Bio-Rad) were coated with $1,1^{\prime}$-dioctadecyl3,3,3',3'-tetramethyl-indocarbocyanine perchlorate (DiI; Invitrogen) and shot through a membrane filter $(3-\mu \mathrm{m}$ pore, Millipore) using a biolistic Helios gene gun (Bio-Rad) at $120-150 \mathrm{psi}$ helium gas, pressure. Sections were rinsed with PBS several times and mounted onto glass slides using ProLong Gold Antifade (Invitrogen). Details of image acquisition and morphological analysis can be found in the study by Dobi et al (2011).

\section{RESULTS}

\section{Abstinence Changes EtOH-Drinking Topography}

Daily EtOH intake (4\% w/v) was monitored across months before each imposed abstinence period (phases 1, 2, and 3; Figure 1a). Analysis revealed that intake differed slightly with average intakes greater in phase $1(2.6 \pm 0.03 \mathrm{~g} / \mathrm{kg}$ per day) and phase $2(2.6 \pm 0.03 \mathrm{~g} / \mathrm{kg}$ per day) than in phase 3 $(2.4 \pm 0.02 \mathrm{~g} / \mathrm{kg}$ per day; $\mathrm{F}(2,22)=20.09, p<0.0001$; Figure $2 \mathrm{a})$. Thus, the group average of daily intakes decreased by $0.2 \mathrm{~g} / \mathrm{kg}$ per day $(\sim 1$ drink per day from an average of 12$)$ by phase 3. After abstinence, the reintroduction of EtOH resulted in a transient ( $<2$ weeks) increase in intakes in only one-third of the monkeys $(25090,25095,25096$, 25097 ), mostly confined to monkeys with the lowest average consumption. After the second abstinence phase, there was little evidence for a transient increase in EtOH intakes in any of the monkeys.

The largest change across phases was a striking decrease in the day-to-day variability of intake, rather than on the average intake (Table 1; Figure 2b). In particular, 10 of the
12 monkeys showed a decrease in the SD of intake (Table 1; Figure $2 \mathrm{~b}$ ) because of either increases in their minimum intake and decreases in maximum intake or exclusively increasing their minimum intake. A test of homogeneity of variance for correlated measures (Zhang, 1998) comparing the variance in drinking before the first abstinence to before the third abstinence revealed a significant decrease in variance $(t(10)=6.01, p=0.0001)$. The decrease in day-today variability in subsequent phases (Figure $2 \mathrm{~b}$ ) seems to provide prima facie evidence that the drinking repertoire is narrowed and more predictable, suggestive of a behavioral pattern shifting from a variable pattern to a more inflexible pattern of drinking.

The shift in the regulation of $\mathrm{EtOH}$ drinking in subsequent phases had a profound effect on BECs. Overall, average-group BECs exhibited progressive increases from phase $1(97 \pm 5 \mathrm{mg} / \mathrm{dl})$ to phase $2(125 \pm 6 \mathrm{mg} / \mathrm{dl})$ to phase 3 $(148 \pm 10 \mathrm{mg} / \mathrm{dl} ; \mathrm{F}(2,22)=23.13, p<0.0001$; Figure 3a). In 11 of the $12 \mathrm{EtOH}$-drinking monkeys, BECs were transiently and robustly increased when EtOH access was reinstated, particularly after the second abstinence period (Figure $3 b$ ). The very large increase in BECs without a change in mean daily intake strongly suggests that the highly regulated intake of EtOH after the second abstinence period associated with maintaining a daily, heavily intoxicated state.

To further understand the factors producing more automated EtOH drinking in subsequent phases, we analyzed the topography of drinking, focusing on bouts of drinking as a stream of repetitious behavior (continuous intake without a 5-min lapse; Grant et al, 2008a). Indeed, the daily bout volumes and durations increased with repeated abstinence. Average bout volumes across all monkeys increased slightly but significantly across phase $1(36 \pm 1 \mathrm{ml})$, phase $2(39 \pm 1 \mathrm{ml})$, and phase $3(38 \pm 0.5 \mathrm{ml}$; $\mathrm{F}(2,22)=-17.44, \quad p=0.001$; Figure 4a). Average bout durations increased linearly after repeated abstinence $(\mathrm{F}(2,22)=39.02, p=0.0001$; phase $1: 182 \pm 3 \mathrm{~s}$; phase 2 : $199 \pm 3 \mathrm{~s}$; phase 3: $206 \pm 3 \mathrm{~s}$; Figure $4 \mathrm{~b}$ ). 

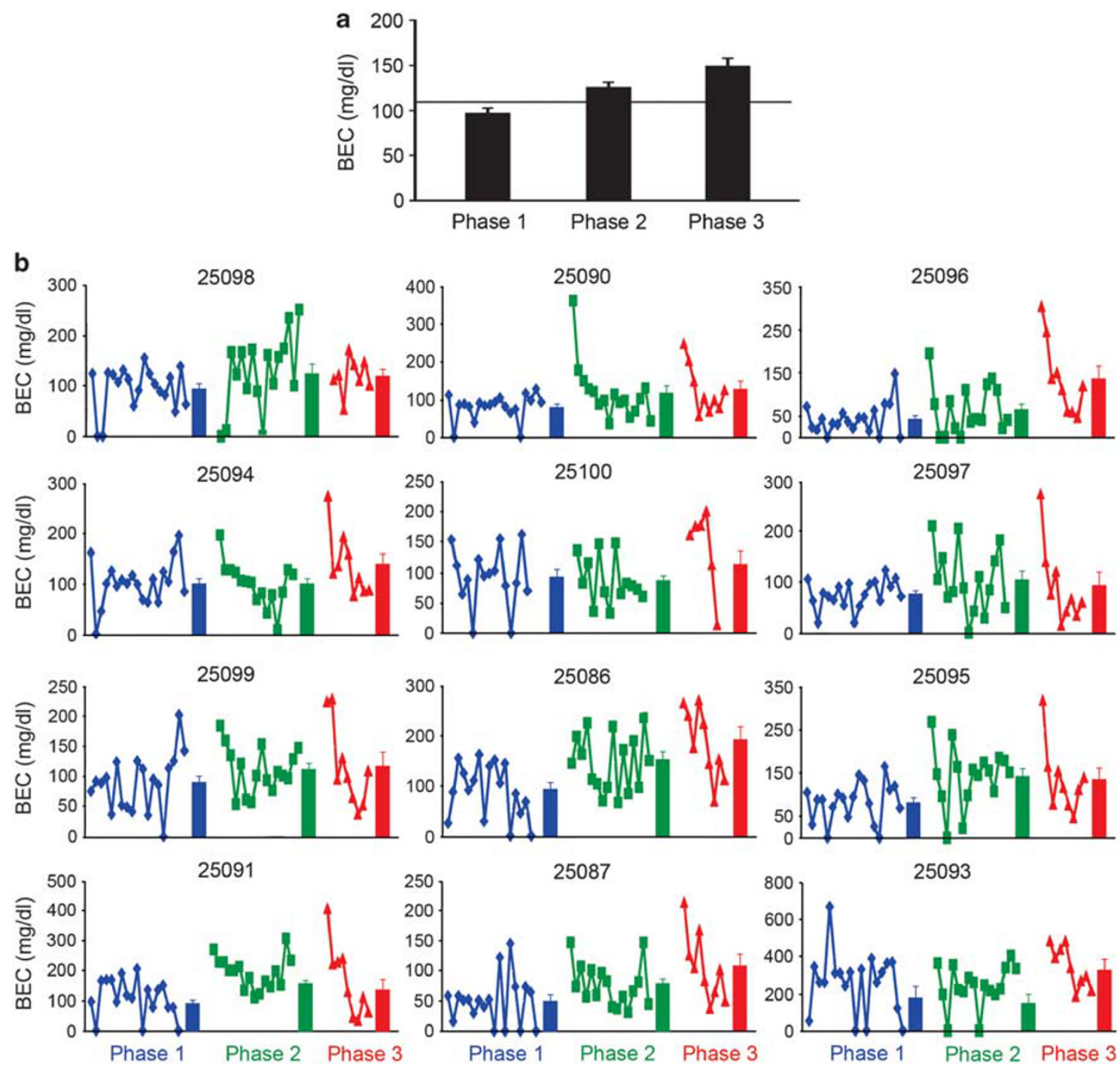

Figure 3 Blood ethanol concentrations in the three pre-abstinent drinking phases. (a) The effect of repeated abstinence on mean ( \pm SEM) BECs. The solid horizontal line indicates baseline BECs averaged over 8 months preceding phase I. (b) The individual and average BEC (solid bars \pm SEM) measurements for individual monkeys during phase I (blue), phase 2 (green), and phase 3 (red) arranged from the lowest (top left) to the highest (bottom right) average daily drinkers.

On an individual basis, the change in drinking patterns in subsequent phases seems to be linked to the increased BECs shown in Figure 3. This is illustrated in Figure 4c by cumulative records of EtOH drinking in monkey 25087 for the first $7 \mathrm{~h}$ of the session (ie, until the BEC sample). These patterns are from two sessions (one in phase 1 and the other in phase 3 ) that were closely matched for total intake at the time of BEC measurement (2.3 and 2.1 $\mathrm{g} / \mathrm{kg}$, respectively). The largest bout in both phases occurs early in the session, but in the third phase, the volume and duration of bouts increased, whereas the number of bouts decreased compared with that in phase 1 (Figure 4d).

Across monkeys, the average bout volume showed a significant positive correlation with average BEC $(r=0.32$, $p<0.001)$ and bout duration $(r=0.45, p<0.001)$ within each phase (data not shown). Furthermore, the correlation of BEC with the volume ingested in the largest bout of the daily session was greatly enhanced in each phase $(r=0.49$, $p<0.001$; data not shown), suggesting that this single behavioral parameter could account for a significant proportion of the variance in BECs. These correlations suggest that changes in bout topography can predict higher BECs and therefore greater intoxication.

Prolonged EtOH drinking with repeated abstinence resulted in decreased water bout volume $(\mathrm{F}(2,22)=16.1$, $p<0.0001$; Figure 4e) and bout duration $(\mathrm{F}(2,22)=11.5$, $p=0.0004$; Figure 4f). Mean water bout volume and duration were greater during phase 1 than during phases 2 and 3 , but phases 2 and 3 did not differ. Water consumption was not correlated with BECs. Food intake was constant over the course of the experiment, including the induction period (data not shown). The monkeys gained an average of $1.78 \pm 0.61 \mathrm{~kg}$ over the entire length of the protocol and they gained an average of $0.50 \pm 0.30 \mathrm{~kg}$ from the first day of abstinence 3 to necropsy.

Signs of physical dependence were noted during the abstinence periods, and were particularly prominent during 

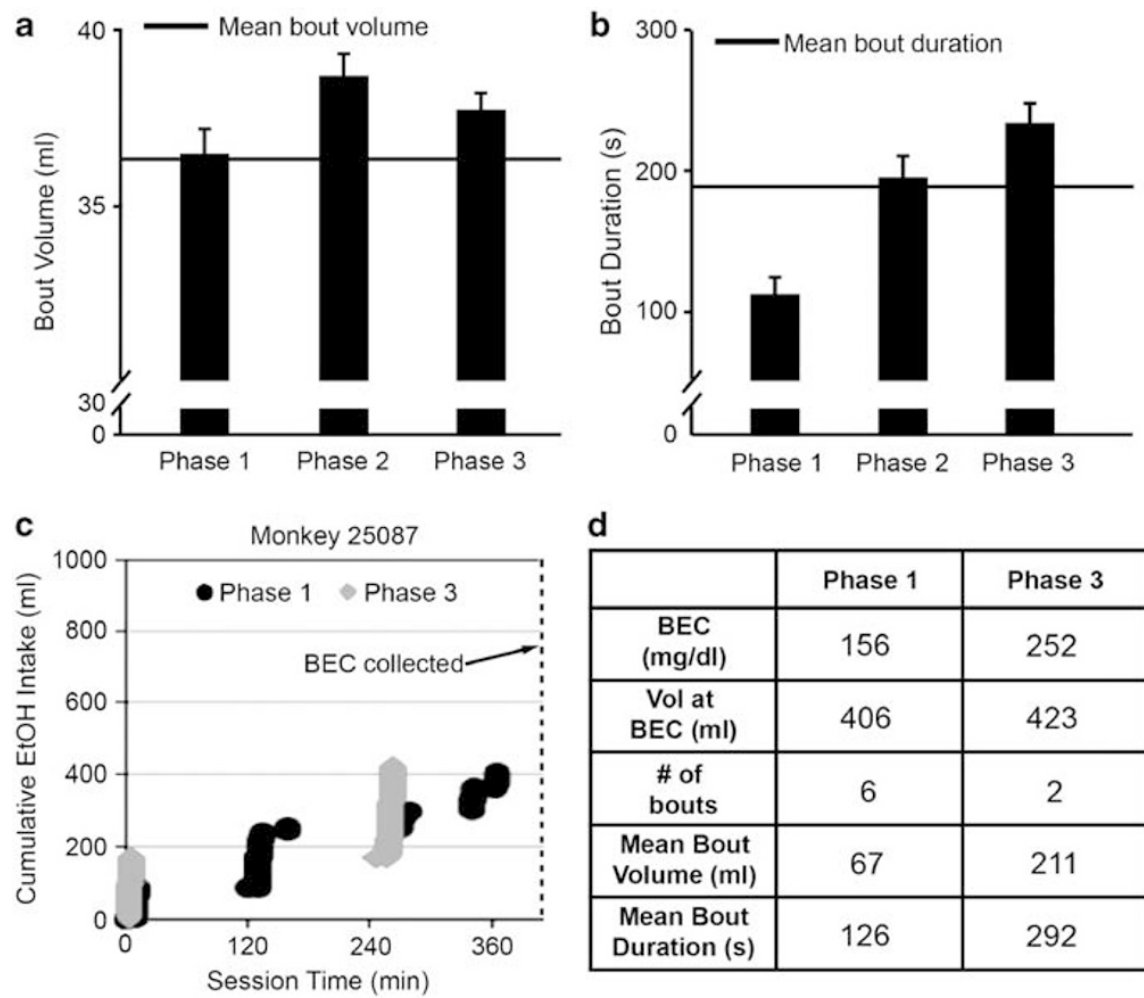

d
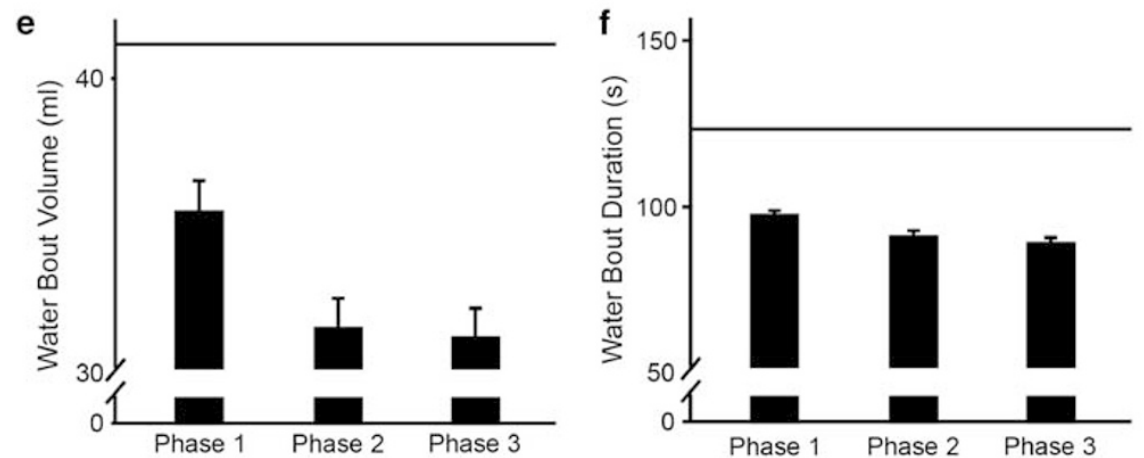

Figure 4 Repeated abstinence effects on drinking characteristics. (a and b) Effects of repeated abstinence on mean ( \pm SEM) bout volumes (panel a) and bout durations (panel b). The horizontal lines indicate baseline measures of bout volume (panel a) or bout duration (panel b) averaged over 8 months preceding phase I. (c) Cumulative records of drinking in phases I and 3 of monkey 25087 chosen for matched total intake at the time of BECs (dashed line). (d) Key variables summarizing the drinking patterns in panel c for monkey 25087 during phases I and 3. (e and f) Average water bout volumes (panel e) and water bout duration (panel f) were significantly greater during phase I than during phases 2 and 3 . The horizontal lines indicate baseline measures of water bout volume (panel e) and water bout duration (panel f) averaged over 8 months preceding phase I.

the 24-72 h of 'acute withdrawal' (Figure 5). Furthermore, only one sign seemed to increase (body shake) and one sign remained prominent (huddle) over the repeated withdrawals. On the other hand, the occurrence of normal behaviors increased monotonically within the first abstinence phase, and was highest in the protracted withdrawal for all three abstinence phases.

Cortisol levels after the first 6 and 12 months of openaccess alcohol self-administration were lower compared with baseline and induction phases, but not statistically different (Figure 6). However, after additional EtOH self-administration with interspersing abstinence periods, cortisol levels were significantly decreased in the active drinking phase 3 (Figure 6; $p<0.02$ ). During abstinence (at $48 \mathrm{~h}$ and on the 18th day), cortisol levels increased above EtOH naive baseline and above levels when drinking daily resumed (Figure 6). Dexamethasone (DEX) suppression reduced all cortisol values to the same extent in absolute terms, thus showing strong suppression during abstinence (reduced to $19-22 \%$ of baseline across all 6 abstinent time points) and weak reduction during drinking (reduced to 59, 60 , and $73 \%$ of baseline at 6 and 12 months of EtOH drinking and at the 4 th month of $22 \mathrm{~h}$ access during phase 3 , respectively). Lower cortisol during active drinking is consistent with data obtained from the study by Wand and Dobs (1991) in humans. Higher cortisol during abstinence has been documented in 28-day abstinent human alcoholics (Sinha et al, 2009), although not all subjects show a robust suppression with DEX as was found in these monkeys, most likely due to differences in DEX dose across species. 

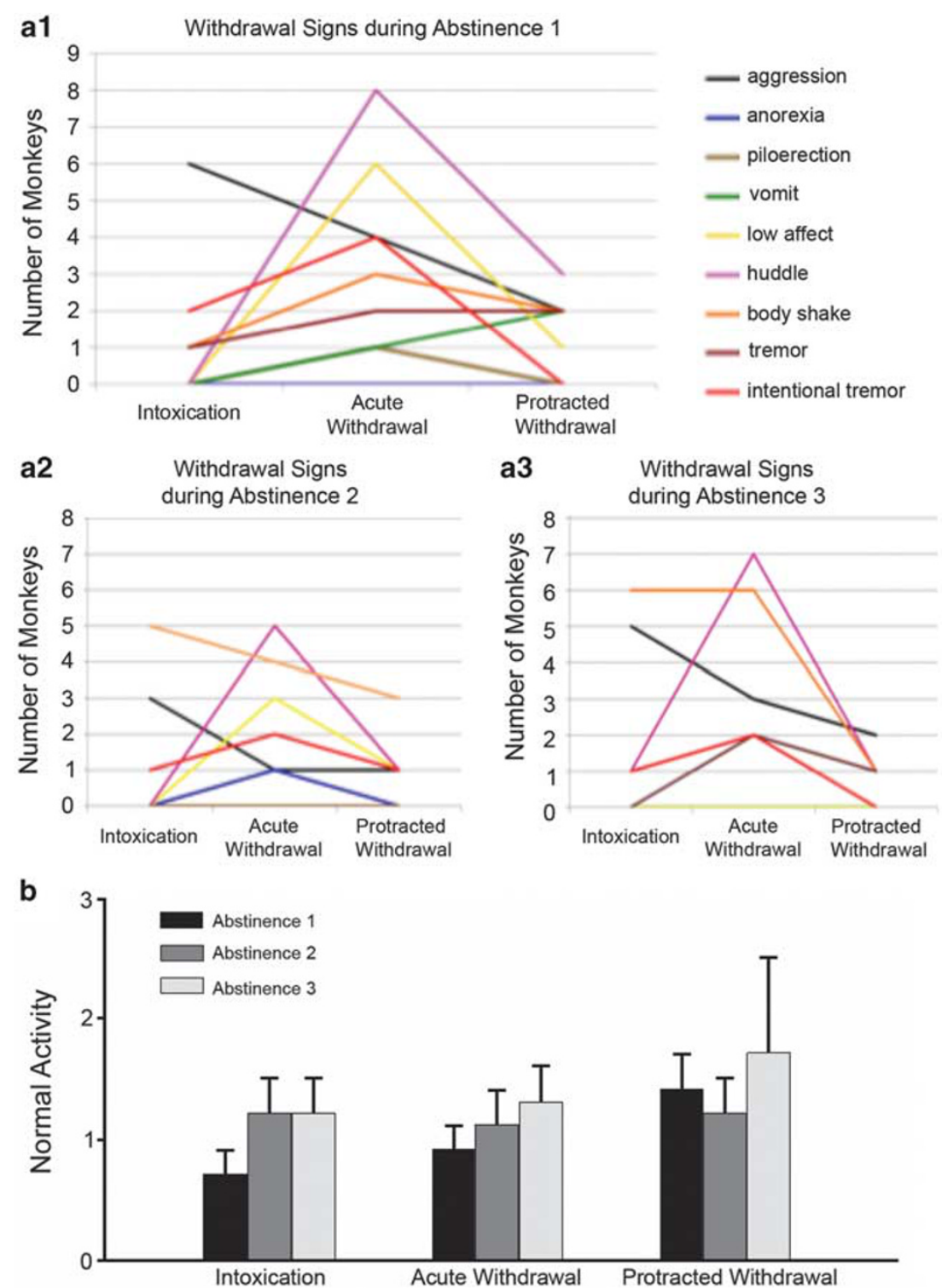

Figure 5 Effects of repeated abstinence on withdrawal signs and normal behaviors. (a) Withdrawal signs observed 3-5 days before abstinence (intoxication), the first 24-72 h of withdrawal (acute withdrawal), and 17-25 days into withdrawal (protracted withdrawal) during abstinence periods I (al), 2 (a2), and 3 (a3). Withdrawal signs were most noticeable during acute withdrawal and diminished in protracted withdrawal, with significantly greater intentional tremors during acute withdrawal $\left(\chi^{2}(2, N=3)=6.2, p=0.046\right)$ and huddling $\left(\chi^{2}(2, N=3)=6.8, p=0.03\right)$. Fewer monkeys showed withdrawal signs in the second and third abstinence compared with the first, except for body shake and huddle, although there were no significant differences between the abstinence periods. (b) Conversely, the normal activity taken at the same time as the withdrawal signs increased in the protracted phase of withdrawal compared with intoxication or acute withdrawal, a trend that was statistically significant during abstinence I $\left(\chi^{2}(2, N=\mid \mathrm{I})=20.2, p<0.000 \mathrm{I}\right)$. There was an increase in normal behaviors in abstinence 3 compared with the first abstinence $\left(\chi^{2}(2, N=33)=21.7, p<0.000 I\right)$.

\section{EtOH Increases MSN Activation and Excitability}

After the final 28 days of abstinence, monkeys were sent to necropsy and brain sections were processed for electrophysiological and morphological analyses. Dendritic spine density and shape were examined in the distal portion of secondary or higher-order dendrites of MSNs from the caudate and putamen of control monkeys (Figure $7 \mathrm{a}$ and $b$ ), and a subset of chronic EtOH drinkers chosen to reflect a range of moderately heavy drinkers (BECs of $93-137 \mathrm{mg} / \mathrm{dl}$ per day; monkey no. $25096,25097,25098$ ) and very heavy drinkers (BECs of $167-347 \mathrm{mg} / \mathrm{dl}$ per day; monkey no. $25086,25091,25093)$. There was no significant difference in spine density between EtOH drinkers and controls in the caudate $(1.07 \pm 0.10$ spines per $\mu \mathrm{m}$ for control and $1.13 \pm 0.05$ spines per $\mu \mathrm{m}$ for EtOH; K-S test; $p=0.16$; Figure 7c1). MSNs analyzed in the putamen of EtOH drinkers exhibited increased spine density compared with controls $(0.88 \pm 0.05$ spines per $\mu \mathrm{m}$ for control and $1.02 \pm 0.06$ spines per $\mu \mathrm{m}$ for EtOH; K-S test; $p=0.04$; Figure $7 \mathrm{c} 2$ and d). In control monkeys, no significant difference was found when comparing spine density of MSNs in the caudate $v s$ putamen (K-S test; $p=0.09$ ). Similarly, no significant difference in the spine length or width was found when comparing all drinkers with their control counterparts in the caudate or the putamen (Figure $7 \mathrm{e}$ and f). 


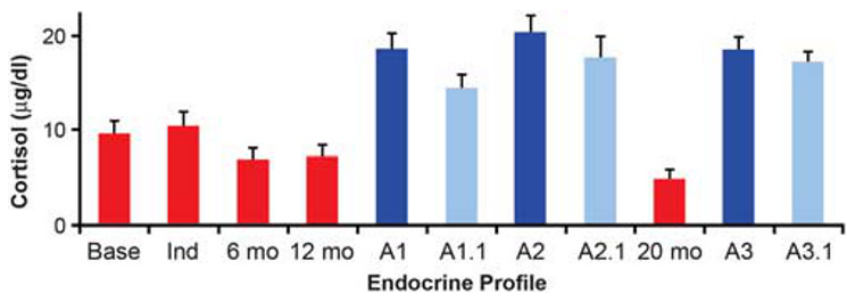

Figure 6 Morning (0800 hours, light on 0600 hours) cortisol measures from male cynomolgus monkeys that underwent repeated withdrawal protocol. These samples were taken before dexamethasone (DEX) treatment. Samples were obtained before induction (base); after 30 sessions of $1.5 \mathrm{~g} / \mathrm{kg}$ per day induced dose of $\mathrm{EtOH}$ (Ind); after 6 and 12 months, respectively, of $22 \mathrm{~h} /$ day self-administration (range of mean daily intakes per monkey was $2.0-5.6 \mathrm{~g} / \mathrm{kg}$ per day or approximately 8-22 drinks per day). 'Al' and 'Al.I' were taken at $48 \mathrm{~h}$ and the I8th day of the first abstinence, respectively. Abstinence was imposed for 28 days. Between Al and $\mathrm{A} 2$, there were 4 months of $22 \mathrm{~h}$ access to $\mathrm{EtOH}$ (cortisol not sampled). After the second abstinence period (again 28 days), cortisol was sampled in the 4th month of $22 \mathrm{~h}$ access to $\mathrm{EtOH}$ (20 months). $\mathrm{A} 3$ and 3.1 were taken at $48 \mathrm{~h}$ and the 18th day of the third abstinence period, respectively. There was a main effect of experimental phase $(F(9,81)=6.7$, $p<0.00 \mathrm{I})$ and pairwise decrease in cortisol at 20 months compared with baseline $(t=2.7, p<0.02)$, and pairwise increase in all samples during all abstinence times compared to baseline (all $p<0.0 \mathrm{I}$ ).

Electrophysiological assessment of glutamatergic synaptic transmission in whole-cell recordings (Figure 8a and b) revealed an increase in the frequency of glutamatergic mEPSCs (observed as a decrease in interevent interval, IEI) in putamen MSNs from EtOH-drinking monkeys $(0.89 \pm 0.12 \mathrm{~s})$ compared with controls $(0.40 \pm 0.08 \mathrm{~s}$; Student's $t$-test; $p<0.01$; Figure $8 c-e)$. This increased frequency could result from increased presynaptic release of glutamate or the number of glutamatergic synapses, as suggested by the increase in spine density. There were no observed differences in mEPSC amplitude, area, rise time, and decay time between MSNs recorded from control and EtOH-drinking monkeys (Figure $8 \mathrm{f}-\mathrm{h}$ ), suggesting a lack of change in postsynaptic responsiveness to glutamate.

We next examined the effects of prolonged intermittent EtOH drinking on GABAergic transmission in the putamen. $\mathrm{GABA}_{\mathrm{A}}$ receptor-mediated mIPSCs recorded from putamen MSNs (Figure 9a and b) of EtOH-drinking monkeys displayed longer IEI compared with controls, suggesting a decrease in GABA release frequency or decreased number of GABAergic synapses (Figure $9 c$ and $d$ ). Interestingly, this change in IEI was positively correlated with daily BECs averaged over phase 3 that preceded necropsy (Figure 9e). The mIPSCs recorded from putamen MSNs of EtOHdrinking monkeys displayed decreases in amplitude and area (Figure $9 \mathrm{f}$ and g), which were not correlated with BECs (data not shown). No change in mIPSC rise or decay time was observed (Figure 9h). These findings suggest that postsynaptic changes are likely due to a decrease in receptor number and not a change in receptor subunit composition as event kinetic characteristics such as decay and rise times were unchanged.

Cortisol levels measured during chronic drinking (after 20 months), early during abstinence $3(48 \mathrm{~h})$, and late during abstinence 3 (18 days) were plotted $v s$ the average spine density, mEPSC IEI, and mIPSC IEI values for each EtOH-drinking monkeys to determine whether any of these measures were significantly correlated. In comparing spine density with cortisol levels measured at the three time points, there was a significant positive correlation only during chronic drinking (Pearson's correlation; chronic drinking: $r=0.77, p=0.04$; early abstinence $3: r=-0.55$, $p=0.13$; late abstinence 3.1: $r=-0.38, p=0.23$; Figure 10a). However, there were no significant correlations between cortisol levels measured at the three time points and mEPSC IEI (chronic drinking: $r=-0.25, p=0.22$; early abstinence 3: $r=-0.14, p=0.34$; late abstinence $3.1: r=-0.08$, $p=0.40$; Figure 10b). Interestingly, there was a strong inverse correlation between mIPSC IEI and cortisol measurements during late abstinence $3 \quad(r=-0.73$, $p=0.005)$, but not during active drinking $(r=-0.29$, $p=0.19)$ or in early abstinence $(r=-0.42, p=0.10$; Figure 10c).

Mechanisms underlying intrinsic MSN excitability may change with prolonged intermittent EtOH intake. Therefore, the membrane properties of putamen MSNs of control (Figure 11a) and EtOH-drinking monkeys (Figure 11b) were examined. Although there was no change in membrane capacitance, suggesting similar size of MSN cell bodies (Figure 11c), input resistance was decreased in MSNs from EtOH drinkers compared with controls (Figure 11d). Overall, MSNs from EtOH drinkers exhibited more depolarized resting membrane potentials and changes in action potential threshold to more depolarized levels (Figure 11e). When MSN membrane potential was briefly stepped to levels exceeding the action potential threshold for $250 \mathrm{~ms}$, the frequency of action potentials was greater in MSNs of EtOH drinkers than in controls (Figure 11f). These findings indicate increased neuronal excitability in putamen MSNs from EtOH-drinking monkeys.

Taken together, our data suggest that prolonged intermittent EtOH drinking decreases GABAergic synaptic transmission while concomitantly increasing glutamatergic transmission in the putamen. This increase in synaptic excitation, combined with increased intrinsic excitability of MSNs, suggests that increased output from the putamen develops with long-term $\mathrm{EtOH}$ intake, likely contributing to the inflexible pattern of EtOH intake.

\section{DISCUSSION}

To gain a better understanding of the neurobehavioral basis of alcohol use disorders, models must share as many features as possible with human alcoholism while still allowing for dissection of the contributing mechanisms. The primate model used here provides evidence that, over a period of years, cynomolgus monkeys choose to drink daily to intoxication, immediately reinstate heavy drinking after prolonged abstinence, and evolve their daily pattern of intake to become more tightly regulated and inflexible, meeting several criteria of human alcohol dependence used in current psychiatric practice (ie, DSM-IV). Furthermore, although our model reveals individual differences in the risk for very heavy drinking ( $>12$ drinks per day) and achieving daily BECs more than twice the legal intoxication limit of $140-300 \mathrm{mg} / \mathrm{dl}$ (Grant et al, 2008b), it also shows that this group of adult male monkeys uniformly narrowed their 

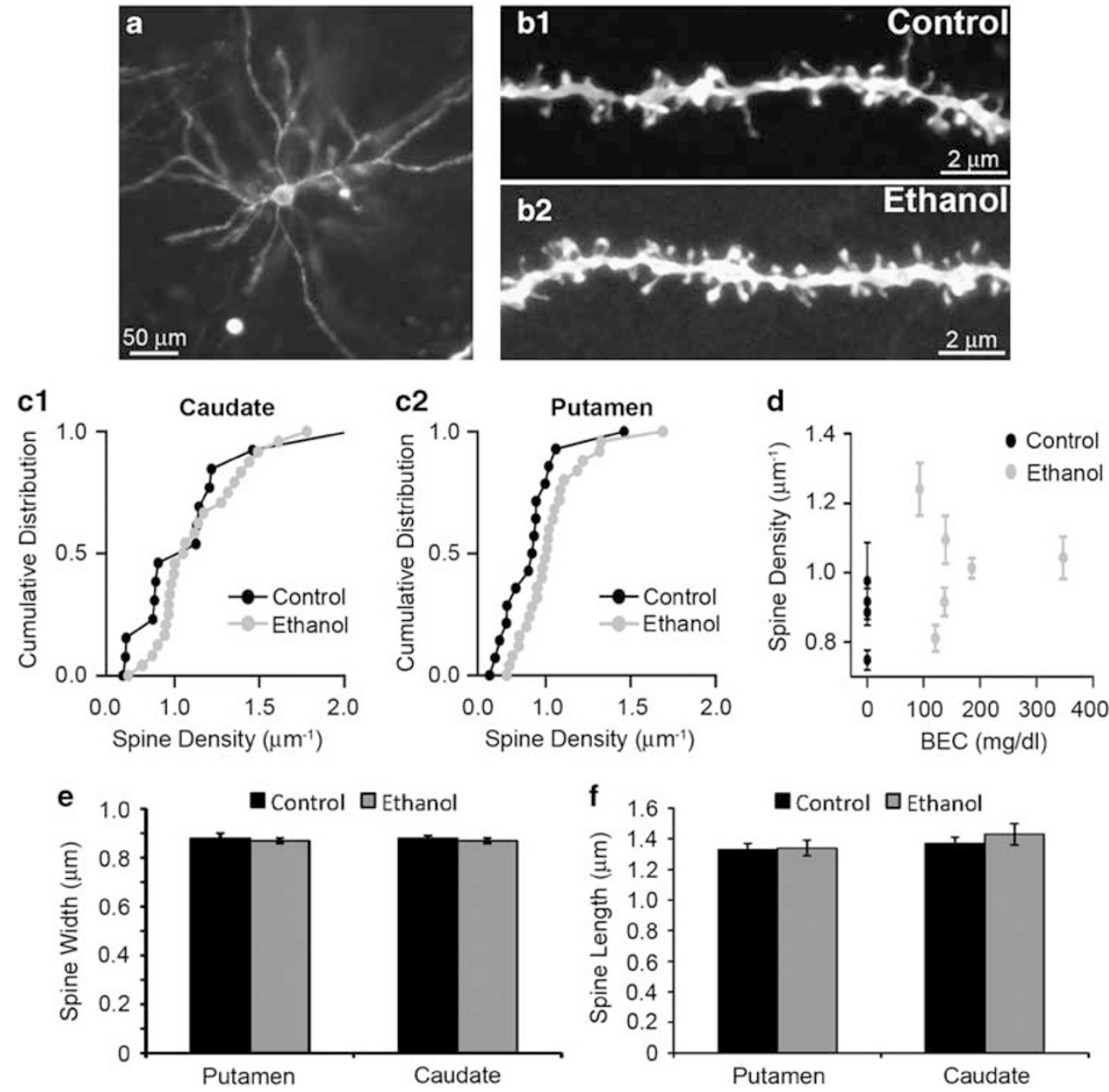

Figure $7 \mathrm{EtOH}$ exposure increases spine density in the monkey putamen but not in the caudate. (a) Example of a putamen MSN labeled using DiOlistics. (b) Confocal image of MSN dendrite in the putamen of control (bl) and EtOH-drinking (b2) monkeys showing dendritic spines. (c) Cumulative distribution of spine densities of MSNs from the caudate ( $\mathrm{cl}$ ) and the putamen ( $\mathrm{c} 2)$ of control and EtOH monkeys ( $n$ for control $=4$ monkeys; $n$ for EtOH-drinking $=6$ monkeys; I5-25 neurons, 44-80 dendrites). (d) Spine density (mean \pm SEM) of MSNs in putamen control and EtOH-drinking monkeys vs mean BECs during phase 3. (e and f) No significant difference in spine width (panel e) and length (panel f) between MSNs analyzed in the putamen and caudate of control (black) and $\mathrm{EtOH}$ (gray) monkeys. (Panel e) Putamen spine length: $1.33 \pm 0.04 \mu \mathrm{m}$ for control and $1.34 \pm 0.05 \mu \mathrm{m}$ for EtOH. Caudate spine length: $1.37 \pm 0.04 \mu \mathrm{m}$ for control and I. $.3 \pm 0.07 \mu \mathrm{m}$ for $\mathrm{EtOH}$. (Panel f) Putamen spine width: $0.88 \pm 0.02 \mu \mathrm{m}$ for control and $0.87 \pm 0.01 \mu \mathrm{m}$ for EtOH. Caudate spine width: $0.88 \pm 0.01 \mu \mathrm{m}$ for control and $0.87 \pm 0.01 \mu \mathrm{m}$ for $\mathrm{EtOH}$. $N=4-6$ monkeys, $43-76$ dendrites; 30-50 spines/dendrite.

drinking repertoire and increased their BECs, across the prolonged $\mathrm{EtOH}$ intake procedure that incorporated repeated abstinence periods.

\section{Relapse and Stereotyped Drinking after Repeated Abstinence}

Within our longitudinal design, we found an effect of repeated abstinence on changes in drinking pattern that reflected a slight decrease in the average daily intake and a large decrease in the variability of these daily intakes, manifested most strongly after the second abstinence period (phase 3). Although the experience of a second imposed abstinence is statistically a main factor in changes to drinking patterns and BECs, we must stress that the cumulative effect of prolonged drinking without abstinence was not measured in this study. Thus, an interaction between duration of drinking and abstinence is a possible contributing factor. Nevertheless, BECs increased in 11 of 12 monkeys after repeated abstinence, even though the distribution of daily intakes ranged from 2.0 to $4.6 \mathrm{~g} / \mathrm{kg}$. Thus, the same effect of repeated abstinence was found across a wide range of chronic intakes, indicating that the level of exposure to EtOH after 20 months of selfadministration was not a key variable in influencing drinking patterns.

One of the characteristics of alcoholism shared by our model is that as dependence progresses, an individual's drinking pattern becomes increasingly predictable and chronic intoxication emerges as a characteristic state (Edwards and Gross, 1976). The monkeys in this chronic EtOH self-administration study initially displayed highly variable daily drinking with both 'spree' drinking $(>16$ drink equivalent) and very 'low' drinking days $(<2$ drink equivalent). Despite the average EtOH intake remaining fairly stable throughout the 3-year study, prolonged drinking with repeated abstinence led to a new regulation of drinking with a decrease in both 'spree' and 'low' 


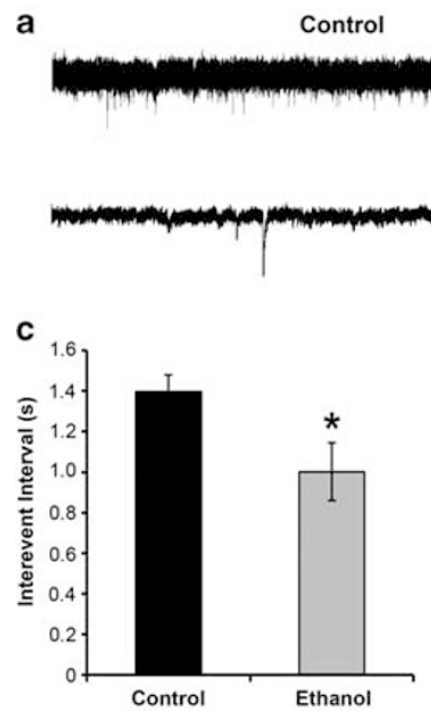

b

Ethanol
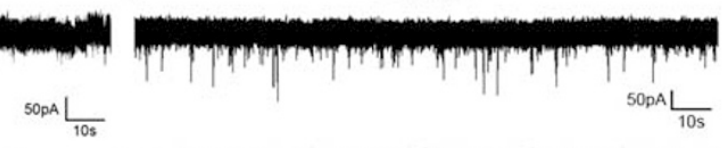

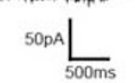

d
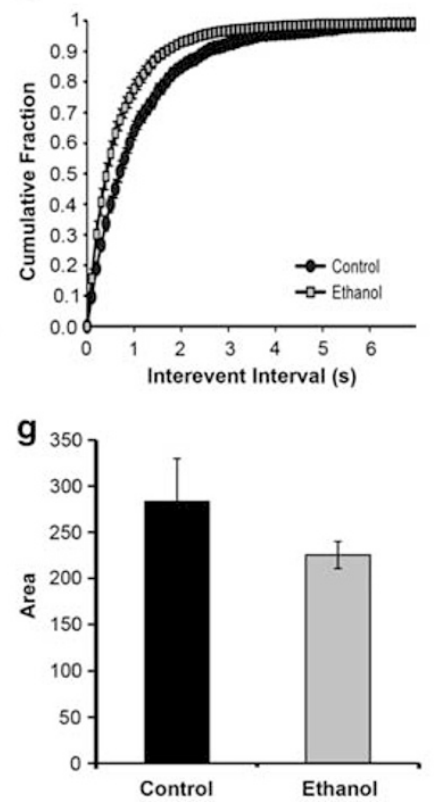
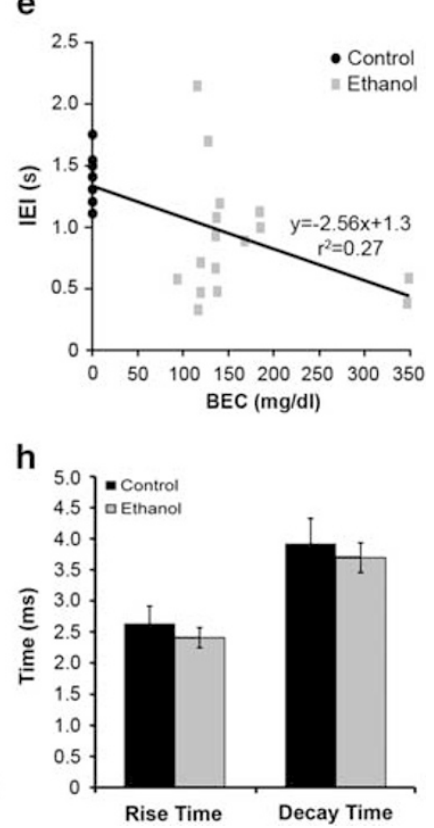

Figure 8 Chronic EtOH exposure with imposed abstinence increases the frequency of mEPSCs. (a and b) Representative mEPSCs recorded from MSNs from control (panel a) and EtOH (panel b) monkeys. (c-h) The average (panel c), cumulative distribution (panel d), and correlation with BEC (panel e) interevent interval (IEI) of mEPSCs measured in putamen MSNs. (Panels e-h) The average amplitude (f), area (g), rise time, and decay time (h) of mEPSCs measured in MSNs.

drinking days and an increase in the duration and volume consumed in bouts leading to a near doubling of BEC. Associated with this more regulated drinking was a decrease in basal cortisol levels, perhaps suggesting that drinking patterns were adapting to stabilize HPA glucocorticoid output in the face of daily intoxication.

As dependence emerges, not only have the positive reinforcing effects of $\mathrm{EtOH}$ been well established but the adverse dependence and withdrawal experiences may also provide additional motivation to perpetuate $\mathrm{EtOH}$ consumption sufficient to prevent or alleviate dysphoric symptoms of withdrawal (Edwards, 1990; Stockwell, 1994; Koob and LeMoal, 2001; Koob, 2003). Although our study did not specifically examine the relationship between withdrawal symptoms and $\mathrm{EtOH}$ consumption, we observed a consistent increase in symptoms during the first $72 \mathrm{~h}$ and decrease in withdrawal symptoms by the 25th day of abstinence after each phase (Figure 5). Also seen was a small but significant increase in normal cage behavior in prolonged abstinence. Thus, the 'relapse' to drinking after the first and second abstinent phases (Figure $3 \mathrm{~b}$ ) does not seem to be driven by the relief from the presence of overt withdrawal signs. Rather, our data suggest that the dependent individual, given experience with prolonged abstinence, finds and maintains a steady alcohol level rendering them comfortably in a regulated state beyond the possible occurrence of withdrawal symptoms. This regulated state involves strong intoxication, and is associated with tissue damage and behavioral changes and is therefore better described as an allostatic state rather than as a homeostatic state (McEwen, 2008). The observation that the drinking variability does not decline over the course of phase 2 , but only during phase 3 suggests that abstinence, and prolonged drinking, contributes to this behavioral change.

The data show little evidence of an 'alcohol-deprivation effect' (Sinclair and Senter, 1968; Sinclair, 1972; Salimov and Salimova, 1993), which is well-documented in rodent studies. In particular, after daily access to alcohol, depriving rodents of this access for a short period of time and then re-introducing alcohol typically results in a transient increase in consumption that increases with repeated deprivation periods. As seen in Figure 2b, the best evidence for an alcohol-deprivation effect was seen in about onethird of the monkeys, mostly confined to those with the lowest average consumption. This effect was diminished by the second abstinence phase. In rodent models, deprivationinduced increases in intake persist for progressively longer periods as the number of exposure/withdrawal cycles increases (Lopez and Becker, 2005). Unlike rodents, 
a

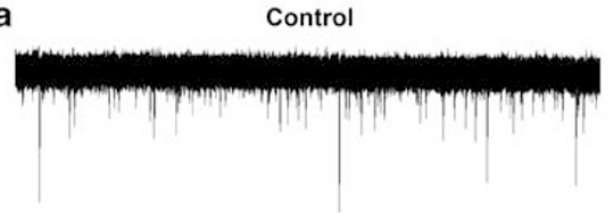

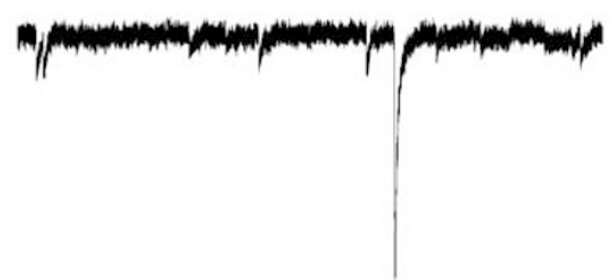
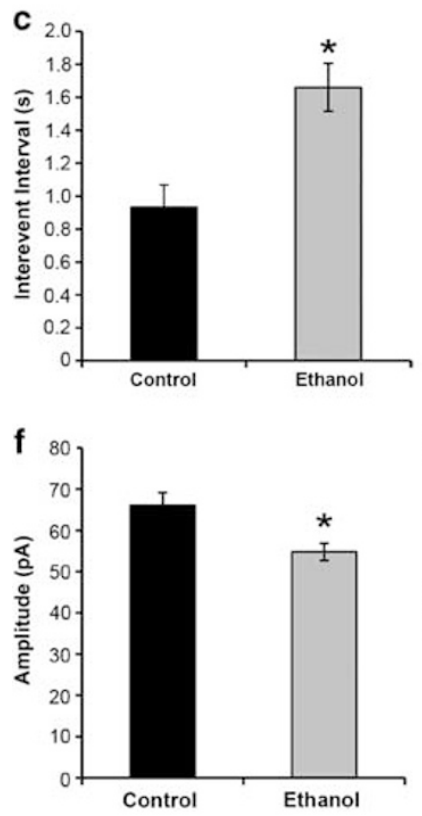

d
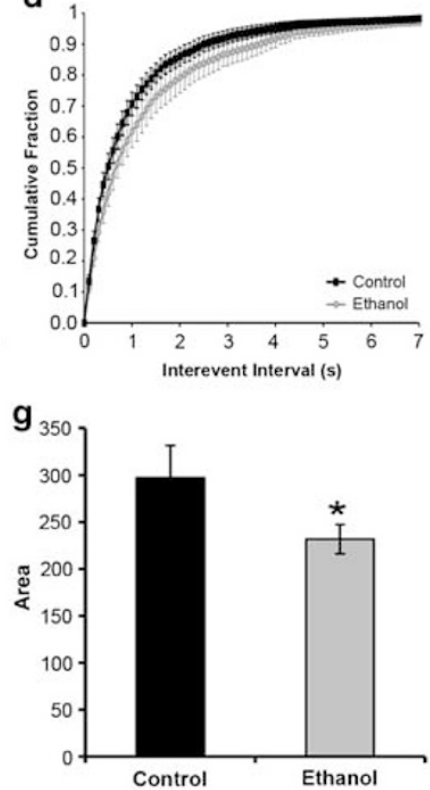

b

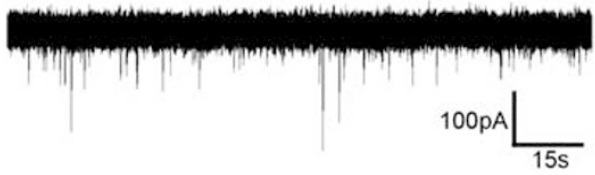

Ethanol
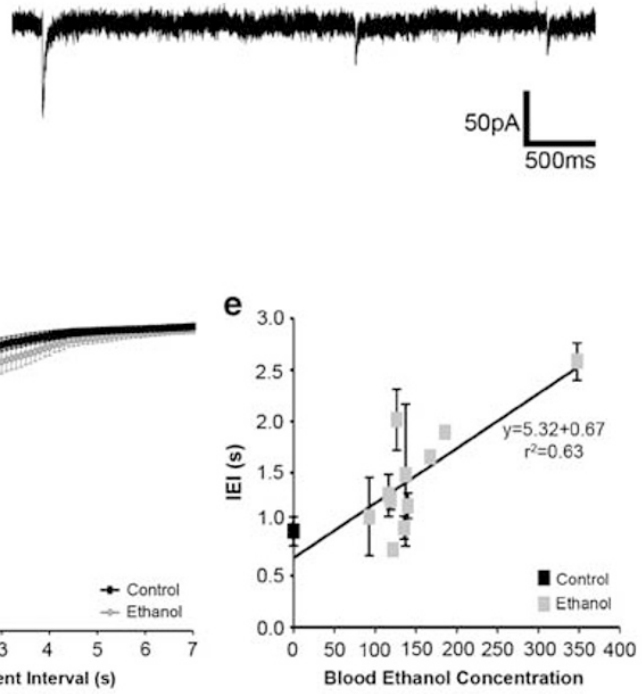

h

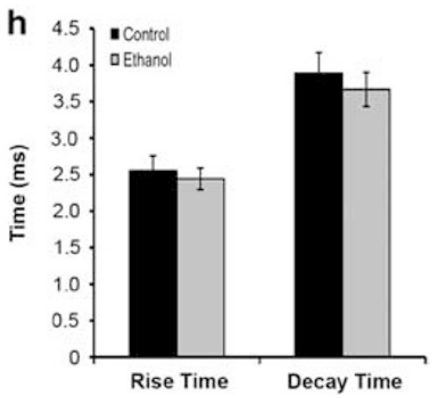

Figure 9 Chronic EtOH exposure with imposed abstinence decreases the frequency and amplitude of mIPSCs in MSNs of the monkey putamen. (a and b) Representative mIPSCs recorded from MSNs in slices obtained from control (panel a) and EtOH (panel b) monkeys. (c-e) The average (panel c), cumulative distribution (panel d), and relationship with blood EtOH concentration (panel e) of mIPSC interevent interval (IEI) measured in control (black) and EtOH (gray) monkeys. ( $f-h)$ The average amplitude (f), area (g), and rise and decay times (h) of mIPSCs measured in MSNs of control and EtOH monkeys. *Statistically significant differences from control at $P<0.05$.

drinking in primates quickly returned to baseline indicating maintenance of a steady level of intake (Figure 2b).

In contrast to the general lack of a deprivation effect on daily intake, BECs obtained after abstinence do show a robust yet transient increase (Figure $3 \mathrm{~b}$ ). Furthermore, BECs measured early in phase 3 drinking were frequently the highest BECs measured in the long drinking histories of these monkeys. The emergent change in drinking topography, specifically the increased duration and volume of intakes in bouts (Figure 4), seems to contribute to the higher post-abstinent BECs (Figure 3b). Drinking in longer and larger bouts reflects an increase in repetitious drinking that may reflect the development of habitual intake patterns. Indeed in a previous examination of long-term EtOH self-administration in cynomolgus monkeys under limited-access conditions (total of $30 \mathrm{~min}$ in a 1-h session), total session intakes remained stable after pre-session administration of EtOH from 0.25 to $1.5 \mathrm{~g} / \mathrm{kg}$ resulting in pre-session BECs of $10-120 \mathrm{mg} / \mathrm{dl}$ (Shelton et al, 2001). Even when primed with enough EtOH to achieve BEC
$>100 \mathrm{mg} / \mathrm{dl}$ for 15 consecutive days, monkeys drank the same volumes of EtOH. In contrast, rodents decrease insession intakes in response to pre-session EtOH administration over a 6-day period (Shelton and Balster, 1997). Therefore, long-term drinking in primates seems to engender a consistent pattern in which drinking alcohol is not controlled by BEC or intoxication level, but rather is controlled by the context, consistent with habitual behavior.

\section{EtOH and Abstinence Effects on the Dorsal Striatum}

Protocols involving forced repeated abstinence have suggested changes in synaptic transmission (Spanagel et al, 1996; Hölter et al, 1997; Heyser et al, 1998; Schmitt et al, 2002; Schroeder et al, 2005; Vengeliene et al, 2005). However, these studies focused on relatively short EtOH exposure, and EtOH-induced effects were not examined in brain regions associated with the regulation of learned behaviors such as alcohol self-administration. The caudoventral area of the primate putamen, similar to the 
a1 Chronic Drinking:
20 months

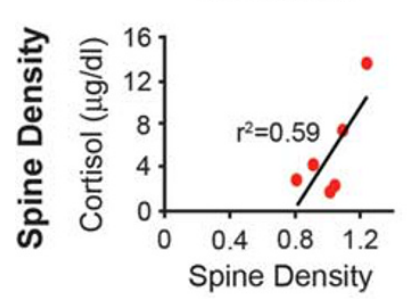

b1

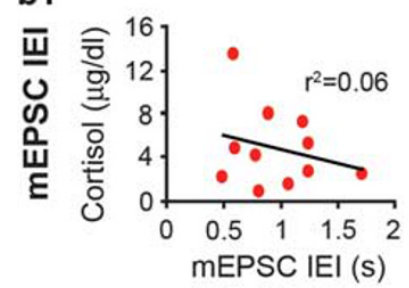

c1

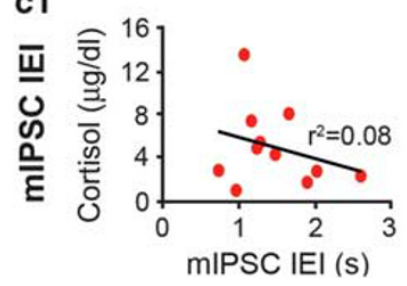

a2

Early Abstinence 3

(48 hours)

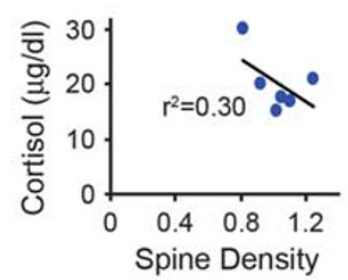

b2

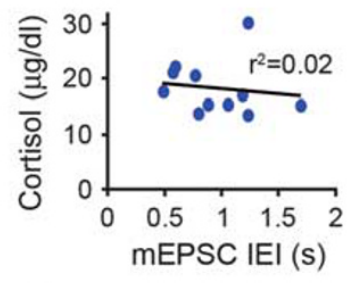

c2

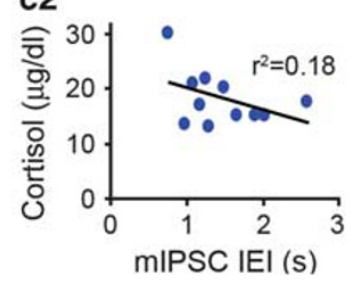

a3 Late Abstinence 3.1

(Day 18)

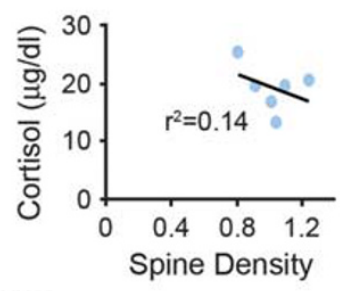

b3
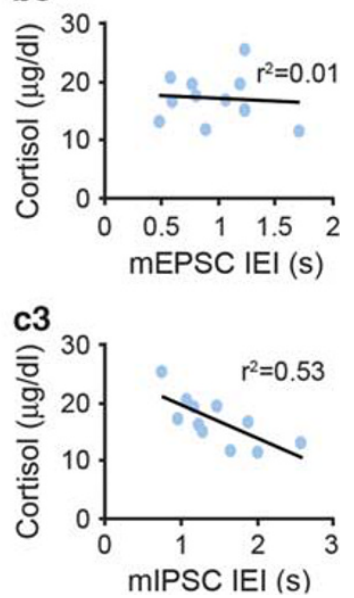

Figure 10 Correlation between cortisol levels measured during chronic drinking and early and late in abstinence 3, and MSN spine density, mEPSC IEI, and mIPSC IEI. ( $a-c$ ) The average spine density (panel a), mEPSC IEI (panel b), and mIPSC IEI (panel c) for each monkey was plotted vs the value of cortisol measured for that individual during chronic drinking (al, bl, cl), early in abstinence 3 (a2, b2, c2), and late in abstinence 3 (a3, b3, c3).

dorsolateral striatum in the rodent, has been implicated in stimulus-response 'habit' learning, leading to automatization of a learned behavior that is believed to be involved in the maintenance of drug use (Tiffany and Conklin, 2000; Gerdeman et al, 2003; Tricomi et al, 2009). On the other hand, the anterior portion of the primate caudate, similar to the dorsomedial striatum in the rodent, appears to be a striatal region involved in the acquisition or moment-tomoment adaptation of learned behaviors in relation to outcome value (Yin et al, 2005a,b; Haber et al, 2006; Gläscher et al, 2009).

As dendritic spines are the sites of excitatory synaptic input (Gray, 1959), increased spine density likely indicates increased number of glutamatergic synapses (Schikorski and Stevens, 1997; Matsuzaki et al, 2001; Yuste and Bonhoeffer, 2001; Nikonenko et al, 2002; Kasai et al, 2003). The evidence for increased frequency of glutamatergic mEPSCs in $\mathrm{EtOH}$ drinkers is consistent with the idea that increased spine density in putamen MSNs renders them more susceptible to synaptic activation.

The decrease in GABAergic synaptic transmission in EtOH-drinking monkeys indicates that synaptic inhibition of MSNs is reduced. This decrease in GABAergic transmission, especially the frequency of mIPSCs, was strongly correlated with BEC values, indicating an association between reduced synaptic inhibition and stereotypic, excessive EtOH intakes. Although $20 \%$ of striatal synapses are GABAergic (Ingham et al, 1988), these synapses have a large role in shaping the output of MSNs. Therefore, the decrease in GABAergic transmission may have a large effect on the output of the putamen and may be an important indicator of the severity of $\mathrm{EtOH}$ dependence. The decreased GABAergic control of MSNs would likely add to or synergize with increased glutamatergic transmission to make the putamen especially vulnerable to activation after long-term intake of high amounts of alcohol. This is likely the state at the end of prolonged abstinence, a set of circumstances that could underlie the stereotypic drinking observed after abstinence in these monkeys.

It should be noted that the morphological and synaptic changes in MSNs were studied only after the final abstinence period. Thus, these changes are not due to the lingering presence of $\mathrm{EtOH}$ or ongoing acute withdrawal symptoms. On the other hand, the frequency of putamen (but not caudate) mIPSCs was inversely correlated with cortisol in late abstinence 3, suggesting a complex interaction between HPA glucocorticoid output and putamen GABAergic synaptic transmission. Furthermore, there was a strong correlation between dendritic spine density in the putamen and cortisol levels during the chronic drinking state of phase $3(r=0.77, p<0.04)$, but not with cortisol levels during prolonged abstinence $(r=-0.38)$. These data raise the possibility that dendritic remodeling is associated with HPA adaptations to chronic drinking rather than abstinence. In rats, chronic intermittent stress (21 days) associated with weight loss and increased habitual behavior has resulted in structural reorganization of both the dorsomedial and the dorsolateral striatum (Dias-Ferreria et al, 2009). The more selective reorganization found in this chronic drinking procedure could be due to chronic 
a

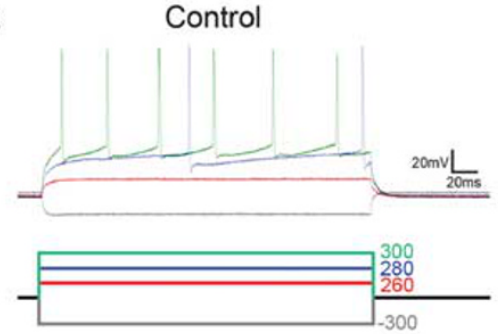

C

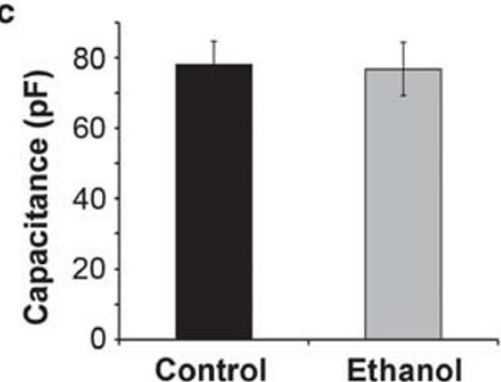

e

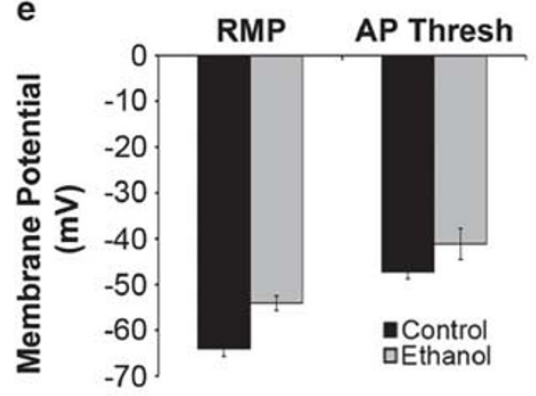

b
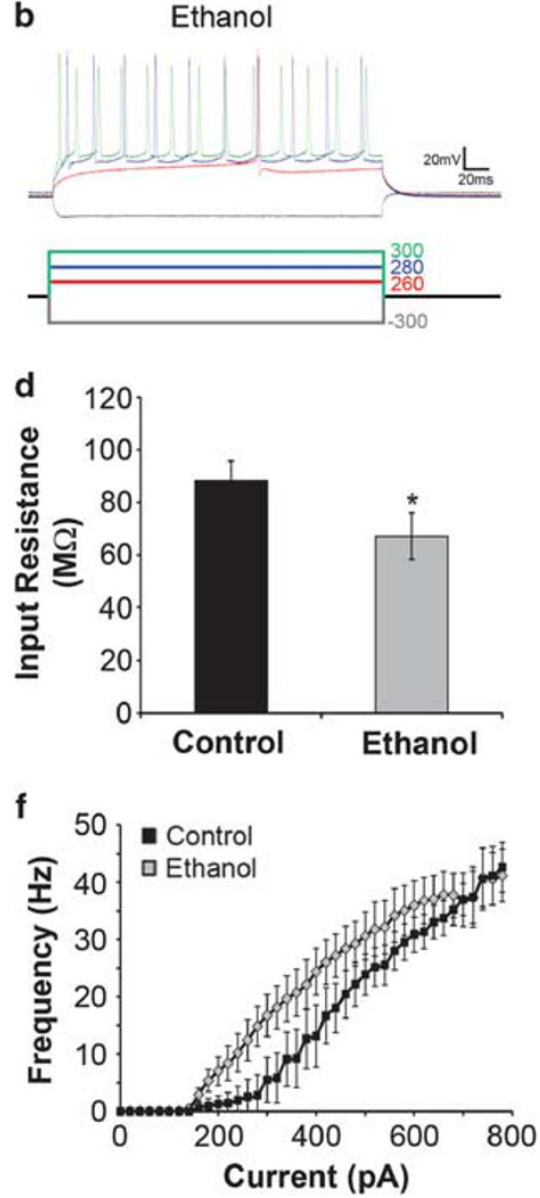

Figure II Intrinsic membrane properties of MSNs recorded from control and EtOH monkeys are slightly different. (a and b) Responses to hyperpolarizing and depolarizing current injections in cells recorded from MSNs from slices obtained from control (panel a) and EtOH (panel b) monkeys. ( $c$ and d) Capacitance (panel c) was unchanged, whereas input resistance was slightly lower in $\mathrm{EtOH}$ than in controls (panel d). (e)The resting membrane potential and the action potential threshold were more depolarized in EtOH compared with controls. ( $f$ ) The relationship between depolarizing current injection and the frequency of action potentials elicited. *Statistically significant differences from control at $P<0.05$.

metabolic, rather than physical, stress of oral ethanol self-administration on HPA adaptation. Overall, the data indicate the presence of long-term alterations in putamen MSN spine density, synaptic transmission, and intrinsic excitability related to the chronic relapsing heavy-drinking phenotype.

\section{Primate $v s$ Rodent Models in EtOH Research}

Aspects of human alcohol drinking and alcohol use disorders, as well as the mechanisms contributing to these behaviors have been modeled and elucidated using rodents. Rodents, especially mice, are coveted because of their rapid reproduction, known genetic background, minimal expense, and potential for genetic manipulation. However, it is difficult to train mice to drink EtOH at a level or pattern similar to human alcoholics, and their short life spans preclude the study of long-term effects of EtOH exposure from several months to years. The use of non-human primate models bypasses these difficulties. Non-human primates are well positioned for comparison with humans in EtOH research because of their 95\% gene homology (Hacia et al, 1998), similar comparative anatomy and physiology, similar EtOH absorption and metabolism
(Green et al, 1999), and their propensity to self-administer large quantities of EtOH orally (Meisch and Stewart, 1994). Monkeys that engage in chronic heavy drinking present liver (Ivester et al, 2007), heart (Cheng et al, 2010), metabolic (Lebold et al, 2011), and CNS (Carden et al, 2006; Hemby et al, 2006; Acosta et al, 2010) abnormalities similar to those seen in human alcoholics.

In conclusion, our findings show that this non-human primate model reproduces both relapse and narrowing of alcohol-related behavioral repertoires that ultimately defend an elevated, consistent alcohol intake. Our study also revealed functional and morphological alterations that seem to reflect pressure to achieve a new homeostasis (or allostasis) in which excitatory inputs gain predominance over inhibitory inputs in the putamen. These observed changes set up increased output from this region that may contribute to highly regulated, inflexible drinking and should prove useful in understanding the transition from heavy drinking to alcoholism.

\section{ACKNOWLEDGEMENTS}

We thank Dr David Rossi for assistance with brain slicing techniques in monkeys, Steven Gonzales for data 
acquisition software development, $\mathrm{Dr}$ Anne Lewis of ONPRC for overseeing the pathology, Dr Ted Hobbs of ONPRC for overseeing the craniotomy, and Dr Larry Sherman of ONPRC for overseeing the electrophysiology core. This study was supported by NIAAA Division of Intramural Clinical and Biomedical Research, AA013510, AA017040, AA013641, and RR000163.

\section{DISCLOSURE}

The authors declare no conflict of interest.

\section{REFERENCES}

Acosta G, Hasenkamp W, Daunais JB, Friedman DP, Grant KA, Hemby SE (2010). Ethanol self-administration modulation of NMDA receptor subunit and related synaptic protein mRNA expression in prefrontal cortical fields in cynomolgus monkeys. Brain Res 1318: 144-154.

Balleine BW, Delgado MR, Hikosaka O (2007). The role of the dorsal striatum in reward and decision-making. J Neurosci 127: 8161-8165.

Becker HC, Lopez MF (2004). Increased ethanol drinking after repeated chronic ethanol exposure and withdrawal experience in C57BL/6J mice. Alcohol Clin Exp Res 28: 1829-1838.

Carden WB, Alexander GM, Friedman DP, Daunais JB, Grant KA, $\mathrm{Mu} \mathrm{J}$ et al. (2006). Chronic ethanol drinking reduces native T-type calcium current in the thalamus of nonhuman primates. Brain Res 1089: 92-100.

Cheng HJ, Grant KA, Han QH, Daunais JB, Friedman DP, Masutani $S$ et al. (2010). Up-regulation and functional effect of cardiac beta(3)-adrenoreceptors in alcoholic monkeys. Alcohol Clin Exp Res 34: 1171-1181.

Daunais JB, Kraft RA, Davenport AT, Burnett EJ, Maxey VM, Szeliga KT et al. (2010). MRI-guided dissection of the nonhuman primate brain: a case study. Methods 50: 199-204.

Delucchi KL, Kaskutas LA (2010). Following problem drinkers over eleven years: understanding changes in alcohol consumption. J Stud Alcohol Drugs 71: 831-836.

Dias-Ferreria E, Sousa JC, Melo I, Morgado P, Mesquita AR, Cerqueira JJ et al. (2009). Chronic stress causes frontostriatal reorganization and affects decision-making. Science 325: 621-625.

Dobi A, Seabold GK, Christensen CH, Bock R, Alvarez VA (2011). Cocaine-induced plasticity in the nucleus accumbens is cell specific and develops without prolonged withdrawal. J Neurosci 31: 1895-1904.

Edwards G (1990). Withdrawal symptoms and alcohol dependence: fruitful mysteries. Br J Addict 85: 447-461.

Edwards G (2010). The trouble with drink: why ideas matter. Addiction 105: 797-804.

Edwards G, Gross MM (1976). Alcohol dependence: provisional description of a clinical syndrome. Brit Med J 1: 1058-1061.

Ellis FW, Pick JR (1971). Ethanol intoxication and dependence in rhesus monkeys. In: Mello NK, Mendelson JH (eds). Recent Advances in Studies of Alcoholism. Publication No. 71-9045 US Gov Printing Office: Washington, DC pp 401-411.

Freeman WM, Gooch RS, Lull ME, Worst TJ, Walker SJ, Xu AS et al. (2006). Apo-All is an elevated biomarker of chronic non-human primate ethanol self-administration. Alcohol Alcohol 41: 300-305.

Freeman WM, Salzberg AC, Gonzales SW, Vrana KE (2010). Classification of alcohol abuse by plasma protein biomarkers. Biol Psychiatry 68: 219-222.

Gerdeman GL, Partridge JG, Lupica CR, Lovinger DM (2003). It could be habit forming: drugs of abuse and striatal synaptic plasticity. TINS 26: 184-192.
Gläscher J, Hampton AM, O’Doherty JP (2009). Determining a role for ventromedial prefrontal cortex in encoding action-based value signals during reward-related decision making. Cereb Cortex 19: 483-495.

Grant KA, Leng X, Green HL, Szeliga KT, Rogers LS, Gonzales SW (2008a). Drinking typography established by scheduled induction predicts chronic heavy drinking in a model of ethanol selfadministration. Alcohol Clin Exp Res 32: 1824-1838.

Grant KA, Stafford J, Thiede A, Kiley C, Odagiri M, Ferguson B (2008b). Who's at risk? Population characterization of alcohol self-administration in nonhuman primates helps identify pathways to dependence. Alcohol Res Health 31: 289-297.

Gray EG (1959). Electron microscopy of synaptic contacts on dendrite spines of the cerebral cortex. Nature 183: 1592-1593.

Green KL, Szeliga KT, Bowen CA, Kautz MA, Azarov AV, Grant KA (1999). Comparison of ethanol metabolism in male and female cynomolgus macaques (Macaca fascicularis). Alcohol Clin Exp Res 23: 611-616.

Haber SN, Kim KS, Mailly P, Valzavara R (2006). Reward-related cortical inputs define a large striatal region in primates that interface with associative cortical connections, providing a substrate for incentive-based learning. J Neurosci 26: 8368-8376.

Hacia JG, Makalowski W, Edgemon K, Erdos MR, Robbins CM, Fodor SP et al. (1998). Evolutionary sequence comparisons using high-density oligonucleotide arrays. Nat Genet 18: 155-158.

Hemby SE, O'Conner JA, Acosta G, Floyd D, Anderson N, McCool BA et al. (2006). Ethanol-induced regulation of GABA-A subunit mRNAs in prefrontal fields of cynomolgus monkeys. Alcohol Clin Exp Res 30: 1978-1985.

Heyser CJ, Schulteis G, Durbin P, Koob GF (1998). Chronic acamprosate eliminates the alcohol deprivation effect while having limited effects on baseline responding for ethanol in rats. Neuropsychopharmacology 18: 125-133.

Hölter SM, Landgraf R, Zieglgänsberger W, Spanagel R (1997). Time course of acamprosate action on operant ethanol selfadministration after ethanol deprivation. Alcohol Clin Exp Res 21: $862-868$.

Ingham CA, Bolam JP, Smith AD (1988). GABA-immunoreactive synaptic boutons in the rat basal forebrain: comparison of neurons that project to the neocortex with pallidosubthalamic neurons. J Comp Neurol 273: 263-282.

Ivester P, Roberts LJ, Young T, Stafforini D, Vivian J, Lees C et al. (2007). Ethanol self-administration and alterations in the livers of the cynomolgus monkey, Macaca fascicularis. Alcohol Clin Exp Res 31: 144-155.

Kasai H, Matsuzaki M, Noguchi J, Yasumatsu N, Nakahara H (2003). Structure-stability-function relationships of dendritic spines. Trends Neurosci 26: 360-368.

Koob GF (2003). Neuroadaptive mechanisms of addiction: studies on the extended amygdala. Eur Neuropsychopharmacol 13: $442-452$.

Koob GF, LeMoal M (2001). Drug addiction, dysregulation of reward, and allostasis. Neuropsychopharmacology 24: 97-129.

Lebold KM, Grant KA, Freeman WM, Wiren KM, Miller GW, Kiley C et al. (2011). Individual differences in hyperlipidemia and vitamin $\mathrm{E}$ status in response to chronic alcohol selfadministration in cynomolgus monkeys. Alcohol Clin Exp 35: 474-483.

Lopez MF, Becker HC (2005). Effect of pattern and number of chronic ethanol exposures on subsequent voluntary ethanol intake in C57BL/6J mice. Psychopharmacology 181: 688-696.

Majchrowicz E, Mendelson JH (1971). Blood methanol concentrations during experimentally induced ethanol intoxication in alcoholics. J Pharmacol Exp Ther 179: 293-300.

Matsuzaki M, Ellis-Davies GC, Nemoto T, Miyashita Y, Iino M, Kasai H (2001). Dendritic spine geometry is critical for AMPA receptor expression in hippocampal CA1 pyramidal neurons. Nat Neurosci 4: 1086-1092. 
McEwen BS (2008). Central effects of stress hormones in health and disease: Understanding the protective and damaging effects of stress and stress mediators. Eur J Pharmacol 583: 174-185.

Meisch RA, Stewart RB (1994). Ethanol as a reinforcer: a review of laboratory studies of non-human primates. Behav Pharmacol 5: 425-440.

Monti PM, Tidey J, Czachowski CL, Grant KA, Rohsenow DJ, Sayette $\mathrm{M}$ et al. (2004). Building bridges: the transdisciplinary study of craving from the animal laboratory to the lamppost. Alcohol Clin Exp Res 28: 279-287.

Myers RD, Stoltman WP, Martin GE (1972). Effects of ethanol dependence induced artificially in the rhesus monkey on the subsequent preference for ethyl alcohol. Physiol Behav 9: 43-48.

Nikonenko I, Jourdain P, Alberi S, Toni N, Muller D (2002). Activity-induced changes of spine morphology. Hippocampus 12: $585-591$.

Porcu P, Rogers LS, Morrow AL, Grant KA (2006). Plasma pregnenolone levels in cynomolgus monkeys following pharmacological challenges of the hypothalamic-pituitary-adrenal axis. Pharmacol Biochem Behav 84: 618-627.

Salimov RM, Salimova NB (1993). The alcohol-deprivation effect in hybrid mice. Drug Alcohol Depend 32: 187-191.

Schikorski T, Stevens CF (1997). Quantitative ultrastructural analysis of hippocampal excitatory synapses. J Neurosci 17: 5858-5867.

Schmitt U, Waldhofer S, Weigelt T, Hiemke C (2002). Free-choice ethanol consumption under the influence of GABAergic drugs in rats. Alcohol Clin Exp Res 26: 457-462.

Schroeder JP, Overstreet DH, Hodge CW (2005). The mGluR5 antagonist MPEP decreases operant ethanol self-administration during maintenance and after repeated alcohol deprivations in alcohol-preferring (P) rats. Psychopharmacology 179: 262-270.

Seabold GK, Daunais JB, Rau A, Grant KA, Alvarez VA (2010). DiOLISTIC labeling of neurons from rodent and non-human primate brain slices. J Vis Exp 41: pii: 2081; doi: 10.3791/2081.

Shelton KL, Balster RL (1997). Effects of gamma-aminobutyric acid agonists and $\mathrm{N}$-methyl-D-aspartate antagonists on a multiple schedule of ethanol and saccharin self-administration in rats. J Pharmacol Exp Ther 280: 1250-1260.

Shelton KL, Young JE, Grant KA (2001). A multiple schedule model of limited access drinking in the cynomolgus macaque. Behav Pharmacol 12: 559-573.

Sinclair JD (1972). The alcohol-deprivation effect. Influence of various factors. QJ Stud Alcohol 33: 769-782.

Sinclair JD, Senter RJ (1968). Development of an alcoholdeprivation effect in rats. QJ Stud Alcohol 29: 863-867.

Sinha R, Fox HC, Hong KA, Bergquist K, Bhagwagar Z, Siedlarz KM (2009). Enhanced negative emotion and alcohol craving, and altered physiological responses following stress and cue exposure in alcohol dependent individuals. Neuropsychopharmacology 34: 1198-1208.

Spanagel R, Hölter SM, Allingham K, Landgraf R, Zieglgänsberger W (1996). Acamprosate and alcohol: I. Effects on alcohol intake following alcohol deprivation in the rat. Eur J Pharmacol 305: 39-44.
Stockwell T (1994). Alcohol withdrawal: an adaption to heavy drinking of no practical significance? Addiction 89: 1447-1453.

Tiffany ST, Conklin CA (2000). A cognitive processing model of alcohol craving and compulsive alcohol use. Addiction 95: S145-S153.

Tricomi E, Balleine BW, O’Doherty JP (2009). A specific role for posterior dorsolateral striatum in human habit learning. Eur $J$ Neurosci 29: 2225-2232.

Vengeliene V, Bachteler D, Danysz W, Spanagel, R (2005). The role of the NMDA receptor in alcohol relapse: a pharmacological mapping study using the alcohol deprivation effect. Neuropharmacology 48: 822-829.

Vivian JA, Green HL, Young JE, Majersky LS, Thomas BW, Shively CA et al. (2001). Induction and maintenance of ethanol selfadministration in cynomolgus monkeys (Macaca fascicularis): long-term characterization of sex and individual differences. Alcohol Clin Exp Res 25: 1087-1097.

Walker SJ, Grant KA (2006). Peripheral blood alpha-synuclein mRNA levels are elevated in cynomolgus monkeys that chronically self-administer ethanol. Alcohol 38: 1-4.

Wand GS, Dobs AS (1991). Alterations in the hypothalamicpituitary-adrenal axis in actively drinking alcoholics. J Clin Endocrinol Metab 72: 1290-1295.

Wetterling T, Veltrup C, Driessen M, John U (1999). Drinking pattern and alcohol-related medical disorders. Alcohol Alcohol 34: 330-336.

Winger GD, Woods JH (1973). The reinforcing property of ethanol in the rhesus monkey. I. Initiation, maintenance and termination of intravenous ethanol-reinforced responding. Ann NY Acad Sci 215: $162-165$.

Yin HH, Knowlton BJ, Balleine BW (2005a). Blockade of NMDA receptors in the dorsomedial striatum prevents action-outcome learning in instrumental conditioning. Eur J Neurosci 22: 505-512.

Yin $\mathrm{HH}$, Knowlton BJ, Balleine BW (2006). Inactivation of dorsolateral striatum enhances sensitivity to changes in the action-outcome contingency in instrumental conditioning. Behav Brain Res 166: 189-196.

Yin HH, Ostlund SB, Knowlton BJ, Balleine BW (2005b). The role of the dorsomedial striatum in instrumental conditioning. Eur $\mathrm{J}$ Neurosci 22: 513-523.

Yuste R, Bonhoeffer T (2001). Morphological changes in dendritic spines associated with long-term synaptic plasticity. Annu Rev Neurosci 24: 1071-1089.

Zhang S (1998). Fourteen Homogeneity of Variance Tests: When and How to Use Them Paper presented at the Annual Meeting of the American Education Research Association: San Diego, CA, April 13-17.

This work is licensed under the Creative Derivative Works 3.0 Unported License. To view a copy of this license, visit http://creativecommons.org/ licenses/by-nc-nd/3.0/ 